\title{
DÜBLIN
}

Technological University Dublin ARROW@TU Dublin

\section{Industrial and Agricultural Applications of Solar Heat}

\author{
Brian Norton \\ Technological University Dublin, brian.norton@tudublin.ie
}

Follow this and additional works at: https://arrow.tudublin.ie/ahfrcbks

Part of the Oil, Gas, and Energy Commons, and the Physics Commons

\section{Recommended Citation}

Norton, B. (2012) Industrial and Agricultural Applications of Solar Heat. In Ali Sayigh (ed) Comprehensive Renewable Energy Elsevier. 2012. doi:10.1016/B978-0-08-087872-0.00317-6

This Book Chapter is brought to you for free and open access by the Antenna \& High Frequency Research Centre at ARROW@TU Dublin. It has been accepted for inclusion in Books/Book chapters by an authorized administrator of ARROW@TU Dublin. For more information, please contact arrow.admin@tudublin.ie, aisling.coyne@tudublin.ie,gerard.connolly@tudublin.ie.

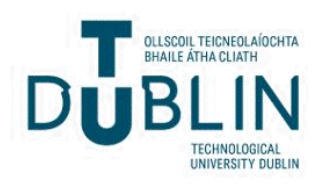


Provided for non-commercial research and educational use.

Not for reproduction, distribution or commercial use.

This chapter was originally published in Comprehensive Renewable Energy,

published by Elsevier, and the attached copy is provided by Elsevier for the author's benefit and for the benefit of the author's institution, for non-commercial research and educational use including without limitation use in instruction at your institution, sending it to specific colleagues who you know, and providing a copy to your institution's administrator.

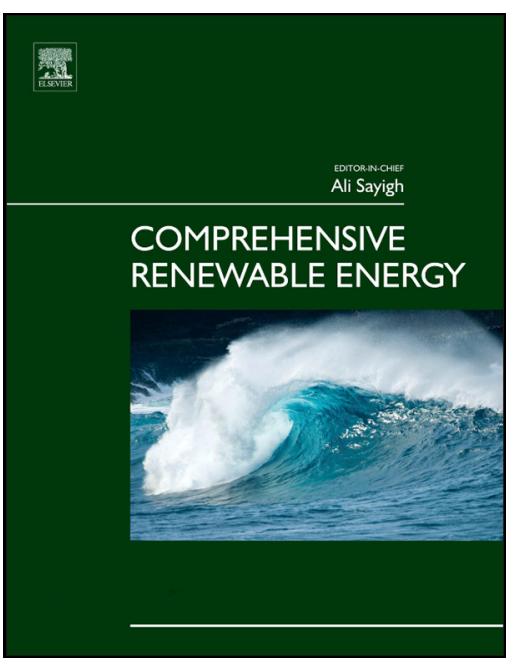

All other uses, reproduction and distribution, including without limitation commercial reprints, selling or licensing copies or access, or posting on open internet sites, your personal or institution's website or repository, are prohibited.

For exceptions, permission may be sought for such use through Elsevier's permissions site at:

\section{http://www.elsevier.com/locate/permissionusematerial}

Norton B (2012) Industrial and Agricultural Applications of Solar Heat. In: Sayigh A, (ed.) Comprehensive Renewable Energy, Vol 3, pp. 567-594.

Oxford: Elsevier.

(c) 2012 Elsevier Ltd. All rights reserved. 


\subsection{Industrial and Agricultural Applications of Solar Heat}

B Norton, Dublin Institute of Technology, Dublin, Ireland

(C) 2012 Elsevier Ltd. All rights reserved.

\begin{tabular}{|c|c|c|}
\hline 3.17.1 & Introduction & 568 \\
\hline 3.17.2 & Characteristics of Industrial and Agricultural Energy Use & 568 \\
\hline 3.17.2.1 & Application Temperatures & 568 \\
\hline 3.17 .2 .2 & Economics & 569 \\
\hline 3.17.3 & Selection of Appropriate Solar Collector and Energy Storage Technologies & 569 \\
\hline 3.17.3.1 & Collector Types & 569 \\
\hline 3.17.3.2 & Aperture Cover Materials & 570 \\
\hline 3.17.3.3 & Flat-Plate Absorbers & 571 \\
\hline 3.17.3.4 & Line-Axis Collectors & 571 \\
\hline 3.17 .3 .5 & Nonconvecting Solar Panels & 572 \\
\hline 3.17 .4 & System Component Layouts & 573 \\
\hline 3.17.4.1 & Components & 573 \\
\hline 3.17.4.2 & Generic Solar Industrial Process Heat System Layouts & 573 \\
\hline 3.17.4.3 & Real Solar Industrial Process Heat Systems & 575 \\
\hline 3.17.4.4 & Operational Limits & 576 \\
\hline 3.17 .5 & Solar Hot Water Industrial and Agricultural Process Heat System Design & 577 \\
\hline 3.17.5.1 & Conceptual Distinctions & 577 \\
\hline 3.17.5.2 & Design Methodologies & 578 \\
\hline 3.17.6 & Solar Drying Technologies & 579 \\
\hline 3.17.6.1 & Solar Drying Processes & 579 \\
\hline 3.17.6.2 & Solar Dryer Types & 580 \\
\hline 3.17.6.3 & Practical Issues in the Use of Solar Dryers & 582 \\
\hline 3.17.6.3.1 & Analysis of solar dryers & 582 \\
\hline 3.17 .7 & Solar Furnaces & 585 \\
\hline 3.17.8 & Greenhouses & 586 \\
\hline 3.17.8.1 & Achieving a Desired Interior Microclimate & 586 \\
\hline 3.17.8.2 & Greenhouse Heating and Cooling & 586 \\
\hline 3.17 .9 & Heating and Ventilation of Industrial and Agricultural Buildings & 587 \\
\hline 3.17.9.1 & Solar Air Heating & 587 \\
\hline 3.17 .9 .2 & Direct Solar Gain and Thermal Mass & 587 \\
\hline 3.17 .10 & Solar Cooking & 588 \\
\hline 3.17 .10 .1 & Types of Solar Cooker & 588 \\
\hline 3.17.10.2 & Analysis of Solar Cookers & 589 \\
\hline 3.17.11 & Solar Desalination & 589 \\
\hline 3.17.11.1 & Solar Desalination Systems & 589 \\
\hline 3.17.11.2 & Passive Basin Stills & 591 \\
\hline 3.17.12 & Solar Refrigeration & 592 \\
\hline 3.17.12.1 & Types of Solar Refrigeration & 592 \\
\hline 3.17.12.2 & Uses of Solar Refrigeration & 592 \\
\hline \multicolumn{2}{|c|}{ Acknowledgments } & 592 \\
\hline \multicolumn{2}{|c|}{ References } & 593 \\
\hline
\end{tabular}

\section{Glossary}

Auxiliary Heating Auxiliary heating is heat provided by non-solar sources to satisfy load requirement during periods when solar energy is unavailable or insufficient. Desalination Desalination describes a range of process that can be used to remove dissolved and suspended material from brackish water to render it potable. Greenhouse A greenhouse is a transparent or semi transparent building that provides a modified environment for plant growth.
Heat Store A heat store returns solar heat for use at times when solar energy is unavailable or insufficient. A heat store can use sensible heat storage via the this temperature elevation of a solid or liquid media. Alternatively the use of phase change materials allows large thermal energy to be retained as latent heat around the phase transition temperature. Solar cooker A solar cooker uses the incident solar radiation to directly or indirectly cook food. 
Solar dryer Solar dryers are a range of devices that convert solar energy to heat that is employed for drying. Solar fraction The solar fraction is the energy fraction of a total energy load that is met by solar energy conversion.
Solar Industrial Process Heat Solar industrial process heat involves the use of solar heated steam, water or air in manufacturing.

\subsubsection{Introduction}

Mankind's earliest use of solar energy was probably the drying of food crops to aid their preservation. Open sun drying of fruit, vegetables, fish and meats often improved or enhanced particular flavors and textures such that solely because of those attributes many dried products remain in culinary use today, as examples, dried seaweed, sun-dried tomatoes, raisins and dried pistachio nuts. Open sun drying is displaced increasingly by glazed solar dryers that (i) enable equilibrium moisture content to be reached sooner and (ii) avoid losses of the crop to insects and rodents.

A further agricultural application, the greenhouse extended the use of solar energy from post-harvest to crop-production. Today greenhouses are ubiquitous with a huge variety of designs providing a wide range of modified climates for plant growth. Solar energy also finds use in agriculture in solar water pumping for irrigation and in the desalination of brackish water.

Solar cooking has taken the use of solar energy in the food production chain directly to the end-user. Broader industrial uses of solar energy have also tended to be linked to food and beverage production because the temperatures required can be satisfied readily in many climates by a well-designed solar thermal system. Non-agricultural technologies such as solar furnaces have considerable potential but have had limited practical use to-date.

This chapter discusses the attributes, contexts and applications of the full range of industrial and agricultural applications of solar heat.

\subsubsection{Characteristics of Industrial and Agricultural Energy Use}

\subsubsection{Application Temperatures}

The use of solar energy in a thermal nondomestic application should ideally be designed, installed, and operated to meet the specific energy and temperature requirements of the particular industrial or agricultural context via an optimal combination of efficient performance, high solar fraction, low initial and running costs, robustness and durability, safety, and environmental sustainability. Industrial processes vary greatly in their required processing temperatures [1]. Figure 1 shows the percentage of process within the particular temperature ranges used by major industrial sectors. The form of presentation in Figure 1 allows solar collectors classified by their type of tracking to be matched to their applicability or otherwise to processes in particular sectors. The data used in Figure 1 are for the United States in 1980. Given the uncertainties associated with continuing global shifts in primary

$\begin{aligned} & \text { Collector } \\ & \text { types }\end{aligned}$
$\longrightarrow$

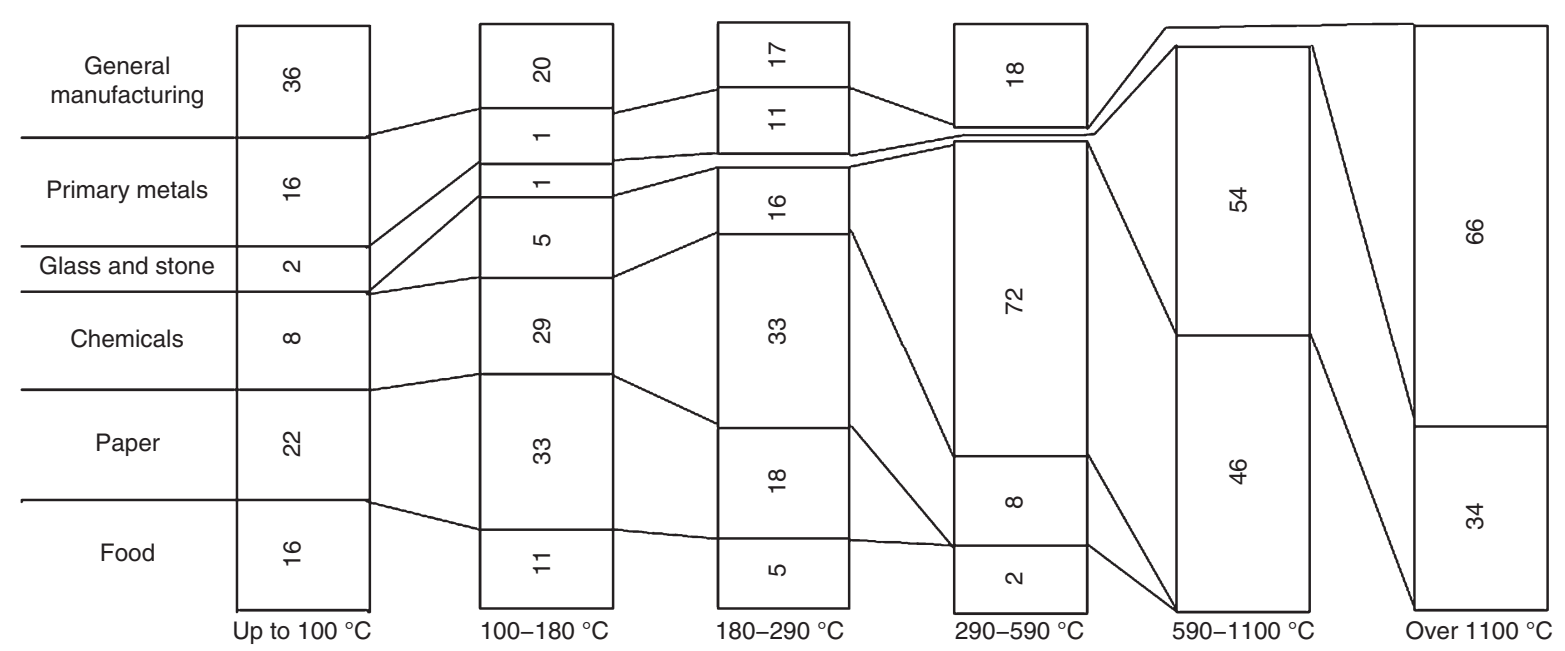

Figure 1 Processing temperatures for industrial sectors. 
Table 1 Process temperatures in low- to medium-temperature solar industrial process applications

\begin{tabular}{lll}
\hline Sector & Process & Required temperature range $\left({ }^{\circ} \mathrm{C}\right)$ \\
\hline Food and beverages & Drying & $30-90$ \\
& Washing & $40-80$ \\
& Pasteurizing & $80-110$ \\
& Boiling & $95-105$ \\
& Sterilizing & $140-150$ \\
& Heat treatment & $40-60$ \\
& Preheating of feedwater to boilers & $30-80$ \\
Textiles & Space heating of factories & $30-100$ \\
& Washing & $40-80$ \\
& Bleaching & $60-100$ \\
& Dyeing & $100-160$ \\
Chemicals & Preheating of feedwater to boilers & $30-80$ \\
& Space heating of factories & $30-100$ \\
& Boiling & $95-105$ \\
& Distilling & $110-300$ \\
& Ancillary processes & $120-180$ \\
& Preheating of feedwater to boilers & $30-80$ \\
& Space heating of factories & $30-100$ \\
\hline
\end{tabular}

manufacturing capacity, the data presented in Figure 1 are probably a reasonable illustration of the pattern of process temperatures associated with particular industry sectors that now prevails worldwide. As can be seen, nontracking collectors, of the flat-plate type (and at higher desired outlet temperature, of the evacuated-tube type) could find ready application across a broad range of sectors (except for the glass and stone processing industries) in the temperature range up to $180^{\circ} \mathrm{C}$.

A more detailed examination of low- to medium-temperature solar industrial processes is provided in Table 1 [2].

At temperatures above $1100{ }^{\circ} \mathrm{C}$, primary metal, glass, and stone production processes dominate and the processing temperatures necessary can only be met directly by solar energy if dual-axis tracking systems are employed to focus insolation onto a solar furnace.

\subsubsection{Economics}

At present, many solar thermal applications are viable economically when particular favorable circumstances of climate and use prevail. More would be so if, for those applications nearing economic viability, the economic externalities associated with the potential for solar energy applications to provide greenhouse gas abatement [3] were given tangible value by appropriate fiscal interventions. Most solar energy industrial and agricultural process heat applications generally employ mature technologies with a long history [4] whose engineering design is well understood [5-11]. The unreliability and irregularity of supply together with variable and often high cost of fossil fuels and electricity means that in many hot climates, particularly in remote and/or island locations, many thermal applications of solar energy in agriculture and industry are not only viable economically but are the obvious and preferred approach. The fact that they are not ubiquitous is due to two interlinked factors: (1) lack of widespread system component suppliers and associated design and installation expertise and experience and (2) the often large initial capital cost. The latter is a particular obstacle where the potential user does not have sufficient available capital and/or is unable or unwilling to borrow funds at favorable interest rates. However, often as a consequence of a diverse range of governmental market stimulation interventions internationally, the influences of such limiting behavioral, trading structure, and capital market factors are, in specific favorable contexts, now being superseded by recognition of the tangible commercial advantages of solar energy use. These include, for example, the often minimal or nonexistent recurrent outlays for fuel, leading to predictable running costs that are a hedge against inflationary energy costs adversely affecting business competitiveness.

\subsubsection{Selection of Appropriate Solar Collector and Energy Storage Technologies}

\subsubsection{Collector Types}

Instead of solar heat being provided by a separate and distinct solar energy collector, harnessing solar energy is often an inherent and intrinsic attribute of many agricultural systems that use solar energy, for example, greenhouses and integral solar dryers. Distinct solar energy collectors are usually employed in most industrial applications. Solar collectors can be either concentrating or flat-plate types and can be either stationary or can track solar position azimuthally (often using fairly simple sensors [12]) in either one or two axes. A classification of principal generic solar collector types is provided in Figure 2. 


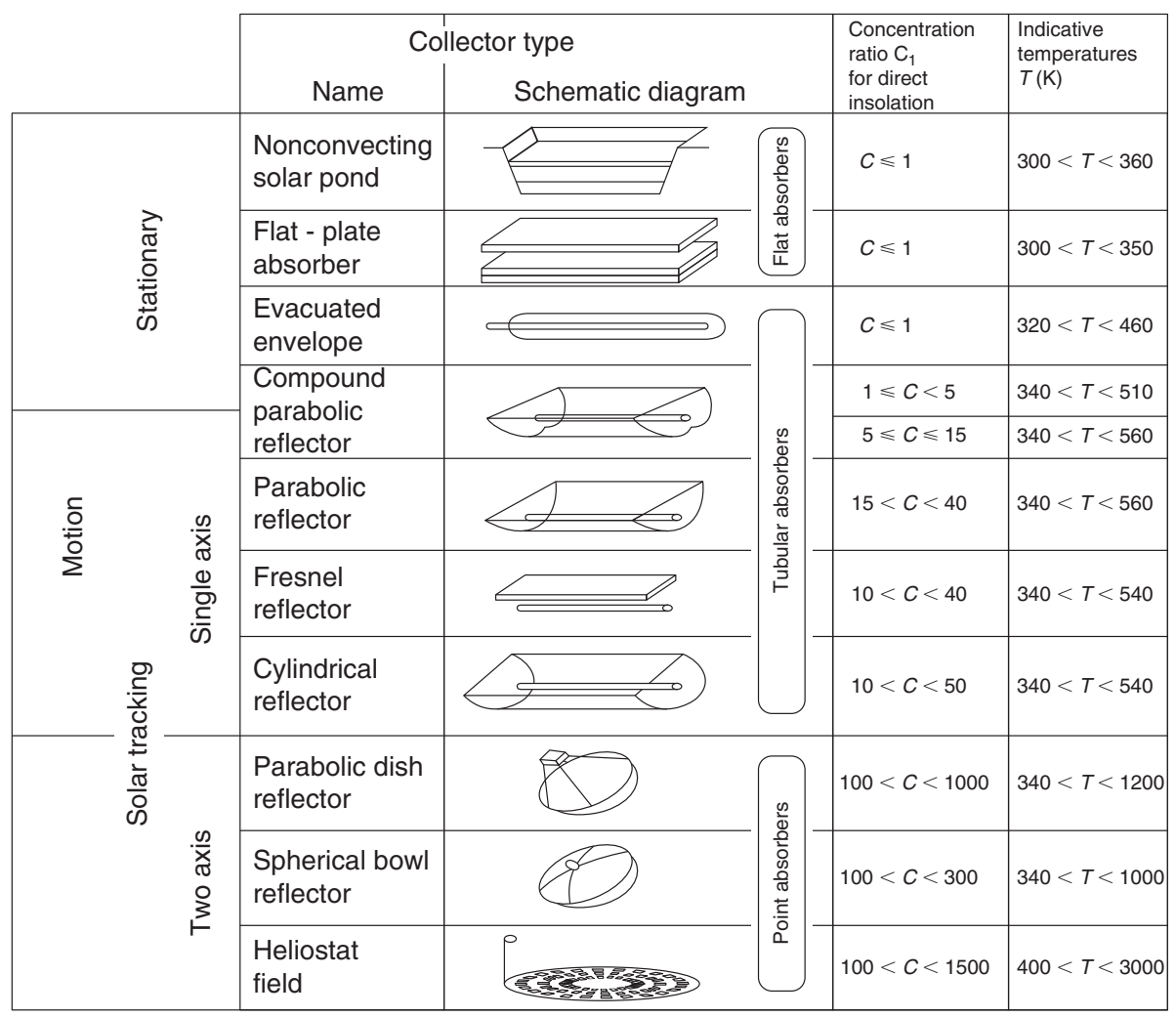

Figure 2 Classification of solar collectors [8].

A flat-plate collector absorber plate gains heat from the incident insolation and transmits it to a working fluid, commonly air, water, aqueous glycol solution, or heat transfer oil. In an evacuated-tube collector, each absorber fin is enclosed in a separate cylindrical glass envelope. Evacuation of the envelope prevents convective heat loss from the absorber plate. The choice of the most appropriate collector depends on the temperature required for given applied conditions. For certain low-temperature applications, an unglazed collector may be the best option. For example, a liquid-film solar collector has been demonstrated for salt recovery from agricultural drainage water in the San Joaquin Valley in California, USA [13]. The absorber material in a flat-plate collector, in addition to having a high absorptance of the incident radiation, should also have a low emittance, provide good thermal conductivity, and be stable thermally under temperatures encountered during both operation and stagnation. It should also be durable, have low weight per unit area, and, most importantly, have a reasonably low initial installed capital cost. Apart from the last criterion, many solar collectors for agricultural applications often fail to meet these criteria as they are fabricated from materials that are readily available locally. However, the overriding factor in the choice of materials for the design of cheap and simple solar energy collectors, particularly those that heat air, is low initial cost; thus, in the actuality of practical system realization, certain ideal desired material properties will often inevitably be compromised.

\subsubsection{Aperture Cover Materials}

A good collector aperture cover material should have (1) a high transmittance for the incident insolation spectrum, (2) a low transmittance to infrared radiation in order to effectively trap re-radiated heat from the absorber, (3) for water heaters, stability at high temperatures under stagnation conditions, (4) resistance to breakage and damage, and (5) low cost. The variation of the radiative transmittance of a 'transparent' material is determined by its chemical composition, molecular structure, and method of fabrication. Glass with a low iron content is the most common aperture cover material for solar collectors. It is mostly transparent to insolation but as it is almost opaque to thermal radiation, re-radiation from the absorber plate is reduced. Improved thermal insulation of the aperture of higher temperature application solar collectors is achieved from the use of (1) multiple-glazed flat-plate solar collectors though each glass sheet increases optical losses, (2) vacuum tube solar collectors, and/or (3) increased concentration, rendering smaller the aperture area available to lose heat. Glass has high transmittance to visible light, low transmittance to infrared radiation, and stability at high temperatures [14]. However, it has a relatively high cost, low shatter resistance unless toughened, and relatively large weight per unit area, which also increases the cost of the supporting frames or structures required. This has encouraged the adoption of alternative cover materials such as plastics. However, the strength and flexibility of a plastic film normally depend on the polymer chain length: the longer the chains, the less brittle the material. There are several processes that act to break up long polymer chains that are typically several thousand monomers long. Degradation processes include 
(1) thermal degradation, (2) photodegradation (both involving the migration of hydrogen atoms and the formation of free radicals, thus commonly resulting in depolymerization), (3) oxidation, also resulting in depolymerization, owing to the reaction with oxygen, especially at chain branches, and (4) mechanical degradation, owing to the mechanical breaking of chains, for example, tears, surface scratches, and repeated flexing. Although most plastic films have transmittances to visible light greater than 0.85 , they exhibit very wide variations in transmittance to infrared from 0.01 for polymethyl methacrylate to 0.77 for polyethylene compared to 0.01 for glass. Some plastic materials exhibit translucent diffusion of incident direct-component insolation [15]. The major limitations of plastics are their poor physical stability at high water heating collector operating temperatures and their limited long-term durability primarily due to degradation under ultraviolet radiation. In applications that are open to the environment, condensation on the inner surface of a plastic cover reduces light transmission (when compared with glass) because of the higher angle of contact between water droplets and plastics. However, many plastics are available that have been treated chemically to overcome at least some of these shortcomings for a significant period of their use; for example, polymers containing fluorine compounds have radiation transmission properties and resistance to aging superior to those of polyethylene films. As plastics weigh typically about $10 \%$ of the same area of glass, collectors with plastic covers can be installed on roofs where extensive deployment of heavy collectors with glass apertures would exceed that particular roof's load limits.

\subsubsection{Flat-Plate Absorbers}

The plate and tubes of a flat-plate solar collector are usually made of copper or aluminum, whose high thermal conductivity ensures good heat transport to the heat transfer fluid. A high solar absorptance absorber plate surface should also, to reduce radiative losses, have a relative low emittance to thermal radiation. Such selective surfaces consist of either (1) a thin upper layer that is both highly absorbent to insolation and relatively transparent to thermal radiation; this layer is deposited on a high-reflective surface with low thermal radiation emittance, or (2) a nonselective highly absorbing material coated with a high solar transmittance and high infrared reflectance heat mirror. For example, the commonplace 'black chrome' selective surface is the result of microscopic chromium particles deposited on a metal substrate; long-wave thermal radiation is reflected by the chromium particles, but shorter wavelength insolation passes between the particles. Water heating applications in locations prone to subzero winter ambient temperatures are usually indirect systems with a closed circuit formed between the collector and a heat exchanger located in the store. To avoid winter frost damage in pipework, the heat transfer fluid used most commonly is an aqueous solution of propylene glycol with corrosion-preventing additives [16]. Propylene glycol should be used because it is less toxic than ethylene glycol.

\subsubsection{Line-Axis Collectors}

Evacuated-tube collectors use either direct flow or a heat pipe. With direct flow, the fluid in the primary loop passes through the absorber pipe. The advantage of this arrangement is that a heat exchanger is absent and thus its inefficiencies are avoided. In addition to water heating, direct flow evacuated-tube collectors can be used with heat transfer oils or for direct steam generation. When a heat pipe is used, the condensing fluid in the heat pipe relinquishes its heat to the fluid in the primary circuit via a heat exchanger. Parabolic troughs with concentration ratios ranging from 15 to 30 provide temperatures in the range of $250-400{ }^{\circ} \mathrm{C}$, depending on a high direct component of insolation prevailing. Troughs with concentration ratios in the range $8-15$ can heat fluids to output temperatures between 90 and $250^{\circ} \mathrm{C}$. The latter troughs have smaller aperture widths typically between 0.5 and $2.5 \mathrm{~m}$. For aperture widths of up to $1.5 \mathrm{~m}$, it is feasible to glaze the aperture as shown in Figure 3 to (1) further reduce heat losses (though as evacuated-tube absorbers are invariably used at these temperatures, the heat retention advantage of additional glazing is minimal), (2) maintain high mirror reflectance and specularity as dust and dirt accrual is avoided, and (3) provide structural rigidity. Unfortunately, the inclusion of such an additional glazing also decreases the insolation transmitted to the collector.

For parabolic trough collectors, the whole system moves to track the sun. Alternative concentrator designs have been developed in which only either the reflector or the absorber moves to track the sun. Linear concentrating Fresnel mirror collectors employ an

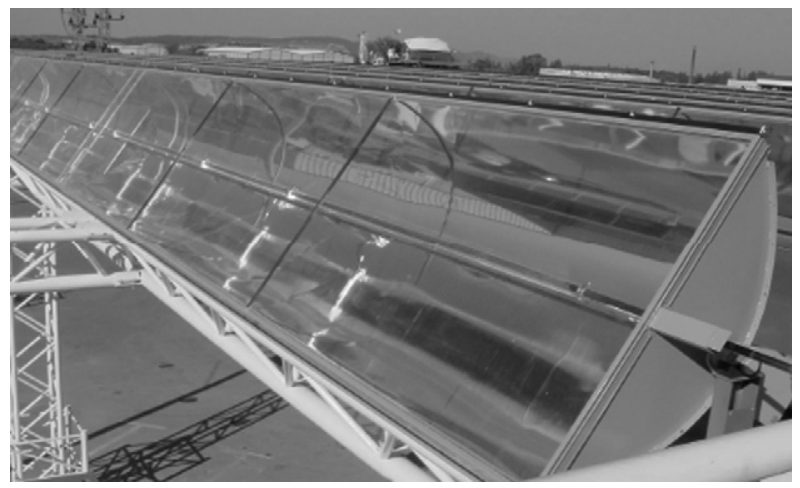

Figure 3 Parabolic trough with aperture glazing. 


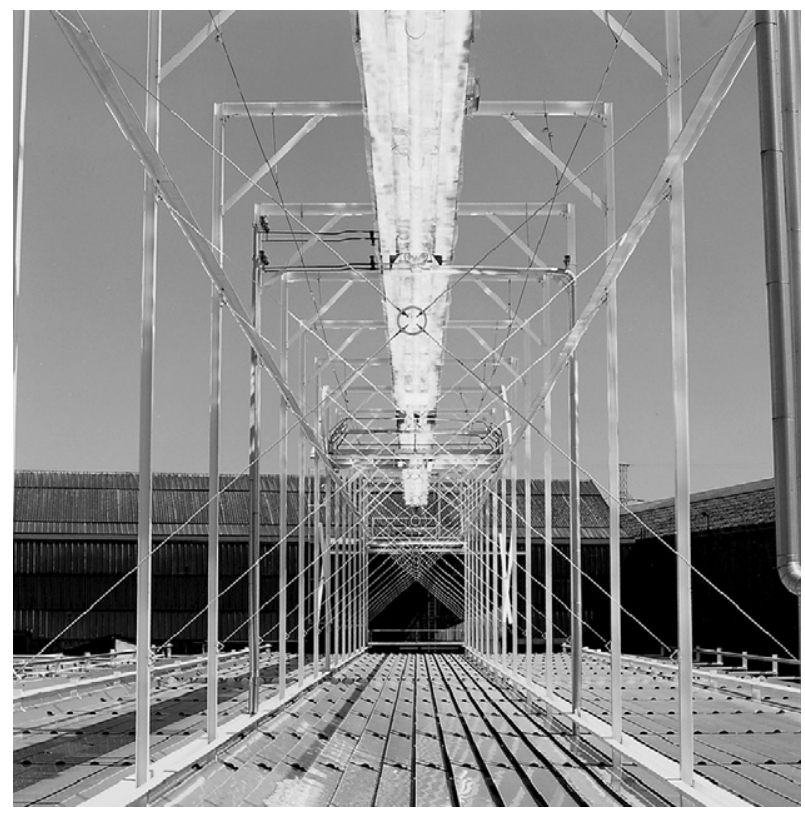

Figure 4 Moving line-axis Fresnel reflectors focusing insolation onto a fixed absorber.

array of mirror strips each of which tracks the sun on a single axis to focus the direct component of incident insolation onto a stationary evacuated-tube absorber within a secondary concentrator as shown in Figure 4. As the absorber is stationary, no fluid couplings are required; this enhances reliability and reduces both initial and maintenance costs.

As the stationary absorber is the only component protruding prominently above the roof or ground level, the wind loading on the system is low. The mirror strips can be located close to each other without mutual shading, so less roof or ground space is wasted when compared with parabolic troughs that require a large spacing between each row of troughs to avoid mutual overshading. Linear concentrating Fresnel mirror collectors have been used for absorption chillers in Italy and Spain [17] and have been placed on a floating rotating base, which gives a two-axis tracking like in a system in Ras al-Khaimah in the United Arab Emirates [18].

In an alternative concept, a stationary arc section of a cylindrical mirror is used to produce a line focus that follows a circular trajectory as the solar incident angle changes. The absorber is moved to be coincident with this line focus [19, 20]. This system also makes efficient use of the available installation area but as a fluid-filled absorber is heavier than mirror strips, more energy is consumed in solar tracking than in a Fresnel mirror system. For systems where either the whole trough/absorber assembly or just the absorber tracks the sun, either flexible or coaxial couplings are required to convey the heated fluid from the absorber.

\subsubsection{Nonconvecting Solar Panels}

Nonconvecting stratified solar ponds are unitary solar energy collectors and heat stores in which part of the incident insolation absorbed is stored as heat in its lower regions [21]. A salt-gradient nonconvecting solar pond consists of three zones: (1) an upper-convecting zone (UCZ), of almost constant low salinity at close to ambient temperature and typically $0.3 \mathrm{~m}$ thick, is the result of evaporation, wind-induced mixing, and surface flushing; wave-suppressing surface meshes and nearby windbreaks keep the UCZ thin; (2) a nonconvecting zone (NCZ), in which a vertical salt gradient inhibits convection providing the thermal insulation that enables temperature to increase with depth; and (3) a lower-convecting zone (LCZ) of typically $20 \%$ salinity by weight at a high temperature in which heat is stored to provide interseasonal heat storage. Algae and cyanobacteria may be deposited by rain and airborne dust and thrive at the temperatures and salt concentrations prevailing in a solar pond. Both algae and cyanobacteria growth inhibit solar transmittance and the latter is toxic. To prevent algae formation, copper sulfate is added at a concentration of $1.5 \mathrm{mg} \mathrm{l}^{-1}$. A solar pond will only function with maintenance of the vertical salt gradient's stratification by controlling the overall salinity difference between the two convecting layers, inhibiting internal convection currents if they form in the NCZ, and limiting the total depth of the pond occupied by the UCZ. For increasingly deep ponds, the thermal capacity increases and annual variations of LCZ temperature decrease. However, the construction of deeper ponds increases both the initial capital outlay and start-up times. The unshaded site for a solar pond should be located close to a cheap source of salt and an adequate source of water, and the cost of land should be low. Nonconvecting solar ponds for industrial heat production tend to be large and so site excavations and preparations may typically account for more than $40 \%$ of the total capital cost. 


\subsubsection{System Component Layouts}

\subsubsection{Components}

A solar energy industrial or agricultural process heat system comprises at the conceptual level a solar collector, intermediate heat storage, and a means of conveying the collected heat between these and to the application. An active system requires a pump to drive the heated fluid through the system, whereas a passive system requires no external power. The term 'integral systems' is used to describe installations where there are no distinct parts performing different functions. For example, in integral solar dryers and cookers, solar energy collection, storage, and use are concurrent in the same part of the system. Most solar hot water industrial and agricultural process heat applications are distributed systems defined as comprising a solar collector, hot water store, and connecting ducts or pipework; they may be either active or passive. The former would describe all medium- to large-scale systems. In a thermosiphon system, fluid flow is due to buoyancy forces produced by the difference in the densities of the fluid in the collector and that of the cooler fluid in the store or application chamber. The applications of thermosiphon solar hot water systems in this context are restricted to small-scale ancillary washing. The shallow solar pond is a low-cost modular, site-built, passive solar water heating system. Each module contains flat water bags on a layer of insulation or sand on the ground. In vineyards, a water-filled 'quilt' placed on the soil surface has been shown to provide effective protection against frost damage to the grapes [22].

The flow-through solar collectors in industrial process heat and agricultural applications are driven usually by a pump or fan. Operating a solar collector at a lower inlet temperature increases its efficiency since it reduces heat losses. The intermediate heat storage may also store heat generated from fossil fuels, and where this is the case, the long-term economically optimal magnitude of, and possibly the need for, the heat store has to be considered against the direct use of fossil fuels at times when there is no output from the solar energy system. The solar collector is selected usually in terms of how the predominant range of outlet temperatures is matched to that of the process heat requirement. Where, and/or at times when, the collector outlet temperature is less than that at the process inlet, additional heating is provided from a heat store or auxiliary sources. Many solar energy industrial and agricultural process applications do not include energy storage because either the diurnal heat load or its sub-daily duration is generally well matched to the available insolation or auxiliary heating may be provided more readily via the combustion of process by-products (e.g., in timber drying solar kilns, wood waste is often used for auxiliary heating). Figures 5-12 show schematic diagrams of a range of generic process system layouts.

\subsubsection{Generic Solar Industrial Process Heat System Layouts}

The simple buoyancy-driven arrangement without recirculation shown schematically in Figure 5 is found typically in simple cabinet dryers. The introduction of a fan, as shown in Figure 6, is necessary in large industrial-scale dryers to overcome the resistance to fluid flow present even when large-diameter duct work is employed. The arrangement in Figure 6 is also used for unglazed transpired air heating solar collectors. As these provide large volumes of warmed air, they are particularly suited to applications with large air

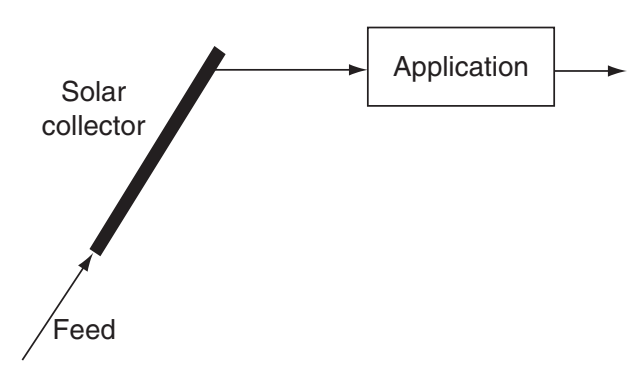

Figure 5 Buoyancy-driven system with heat stored in the application subsystem.

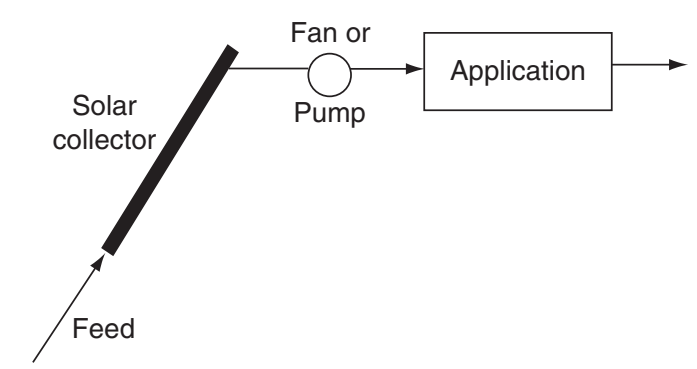

Figure 6 Forced circulation system with heat stored in the application subsystem. 


\section{Author's personal copy}

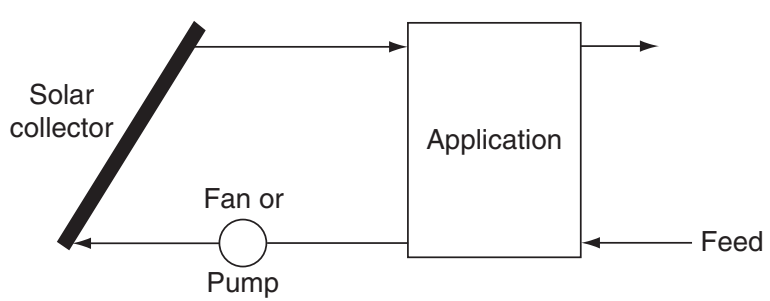

Figure 7 Forced circulation system with return recirculation of the working fluid to the collector.

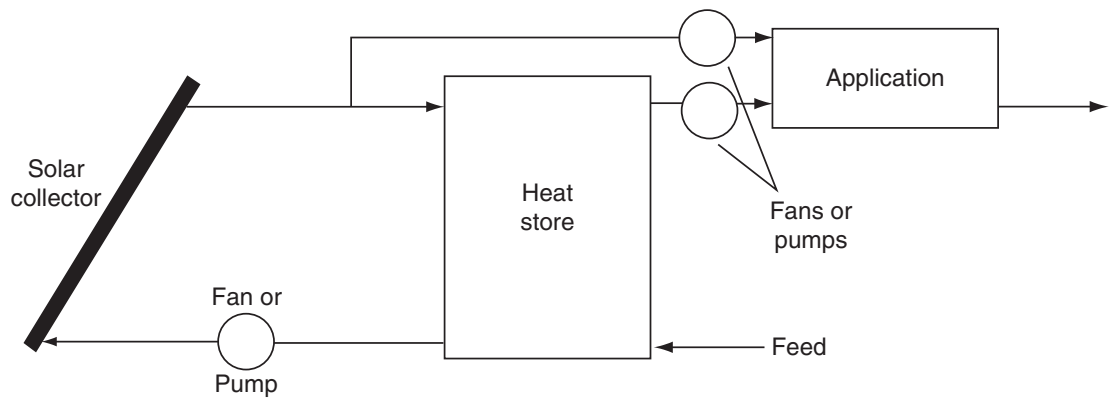

Figure 8 Forced circulation with dedicated heat storage.

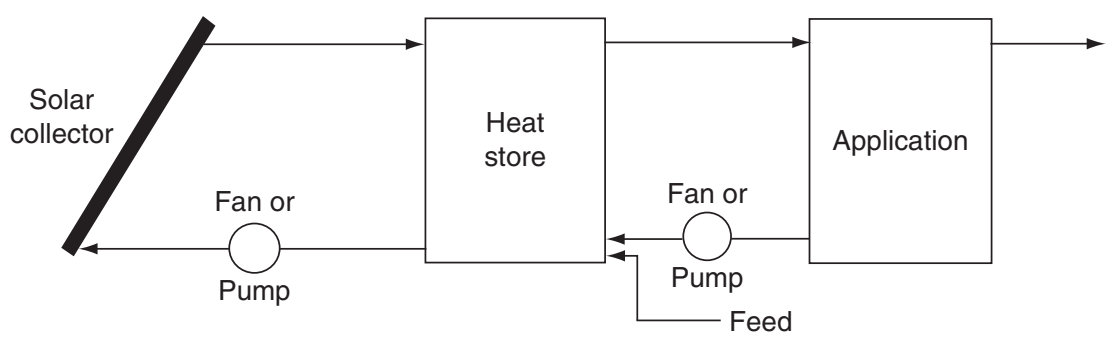

Figure 9 Forced circulation system with recirculation from the store to the collector and from the application to the store.

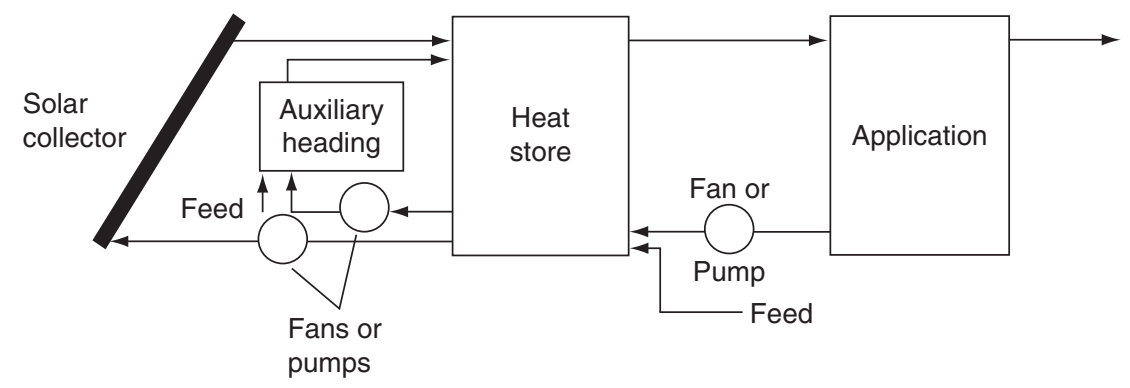

Figure 10 Forced circulation with auxiliary heating of the heat store.

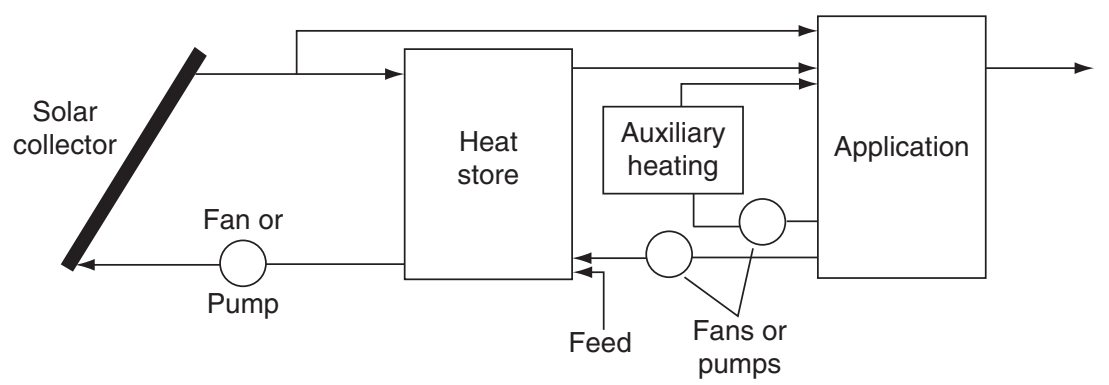

Figure 11 Forced circulation system with auxiliary heating of the application and heat storage. 


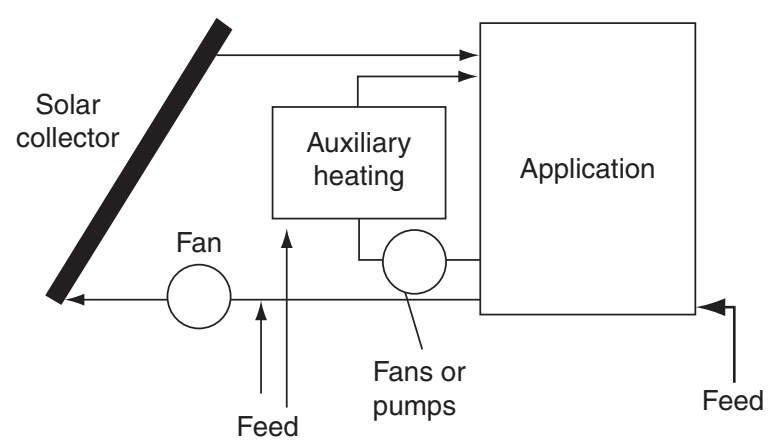

Figure 12 Forced circulation system with auxiliary heating but no dedicated heat storage.

change rates such as the space heating of paint shops. It is preferable in remote locations for the fan or pump shown in Figures 6-12 to be powered by a photovoltaic array. The photovoltaic array provides power to the fan or pump when receiving insolation. No battery is required as the system would not be operated when there is no insolation. The use of a direct current fan or pump obviates the need for, and cost of, including a DC to AC inverter.

The arrangement illustrated in Figure 7 may also be found in air heating applications such as drying or the heating of livestock buildings. Figure 7 also shows the arrangement found typically in most domestic solar water heaters, and is equally applicable to similarly scaled washing and cleaning hot water demands in small enterprises. Water heating systems of the form shown in Figures 7 and 8 will also have other critical components; these include (1) temperature sensors located at the collector inlet and outlet connected to a differential controller that activates the pump at a preset temperature difference, (2) a header tank or other mains pressure controller, (3) in an indirect system, a heat exchanger in the heat store, and (4) pressure relief and nonreturn valves. The colder replenishing fluid enters at the base of the heat store to maintain thermal stratification. Sensible heat storage media are water and for air heating systems, a rock bed or water; in the latter case, an air-to-water heat exchanger is introduced into the secondary circuit.

In the system shown in Figure 8, heat from the collector or the store is conveyed to the application and the fluid then rejected to the ambient environment. The arrangement in Figure 8 would be applicable to intermittent batch processes that would take place only when sufficient fluid has been heated to the required temperature.

In many cases, the fluid may retain some heat after its use in the application. Where this is the case, as shown in Figure 9, some or all of the fluid is recirculated from the application to the base of the store. The proportion of fluid rejected and recirculated can be either fixed or, as is more frequent, altered over time to achieve optimal process conditions. This often requires the extensive deployment of sensors, valves, and controllers in various parts of the layout.

When solar energy is insufficient to meet a heat load either directly or via storage, auxiliary heating is required. It can be introduced into the system layout in the primary circuit as shown in Figure 10, often supplying an additional heat exchanger in the heat store, or for smaller hot water systems, an additional immersed electrical heating element is provided.

Auxiliary heating can also be introduced into a secondary circuit as shown in Figure 11. This layout is common where solar heating is retrofitted to an existing process heat system. Not all aspects of the generic layout shown will be present in particular practical examples. The facility to bypass the store so as to connect the collector directly to the application may often be omitted. This omission can lead, however, to operational inflexibility.

In the system shown in Figure 12, the solar heat is used when available, with auxiliary heating being used at all other times. Not all of the feed options illustrated will be present or (where they are) used in particular practical systems. Certain feed options may come into use only to maintain operation when a particular circuit is undergoing routine maintenance or inspection. The layout in Figure 12 will arise when the life-cycle costs of providing a heat store are higher than those for auxiliary heating. This can be the case for air heating systems where rock-bed stores incur high initial cost due to their heat transfer inefficiency and scale. The layout in Figure 12 without recirculation and auxiliary heating reduces to that shown in Figure 6.

\subsubsection{Real Solar Industrial Process Heat Systems}

Real system layouts for industrial processes are rarely as simple as those shown schematically in Figures 5-12. An illustrative example of a practical layout for a solar-heated brewing process is shown in Figure 13.

Relatively small-scale batch brewing is undertaken using the system shown in Figure 13. Double-glazed collectors of $20 \mathrm{~m}^{2} \mathrm{feed}$ a $1 \mathrm{~m}^{3}$ hot water store. The brewing vessel volume of $400 \mathrm{l}$ enables around $40000 \mathrm{l}$ of beer to be produced annually. The system has been in operation since June 2006. The detailed layout of another closed-loop two-tank system shown in Figure 14 illustrates the typical locations of the valves, sensors, and drains required in practical installations. Local building codes and regulations for the installation of water heating systems will apply. In contrast, the legal requirements for the installation and operation of air heating systems are much less onerous and may be nonexistent in some jurisdictions. 


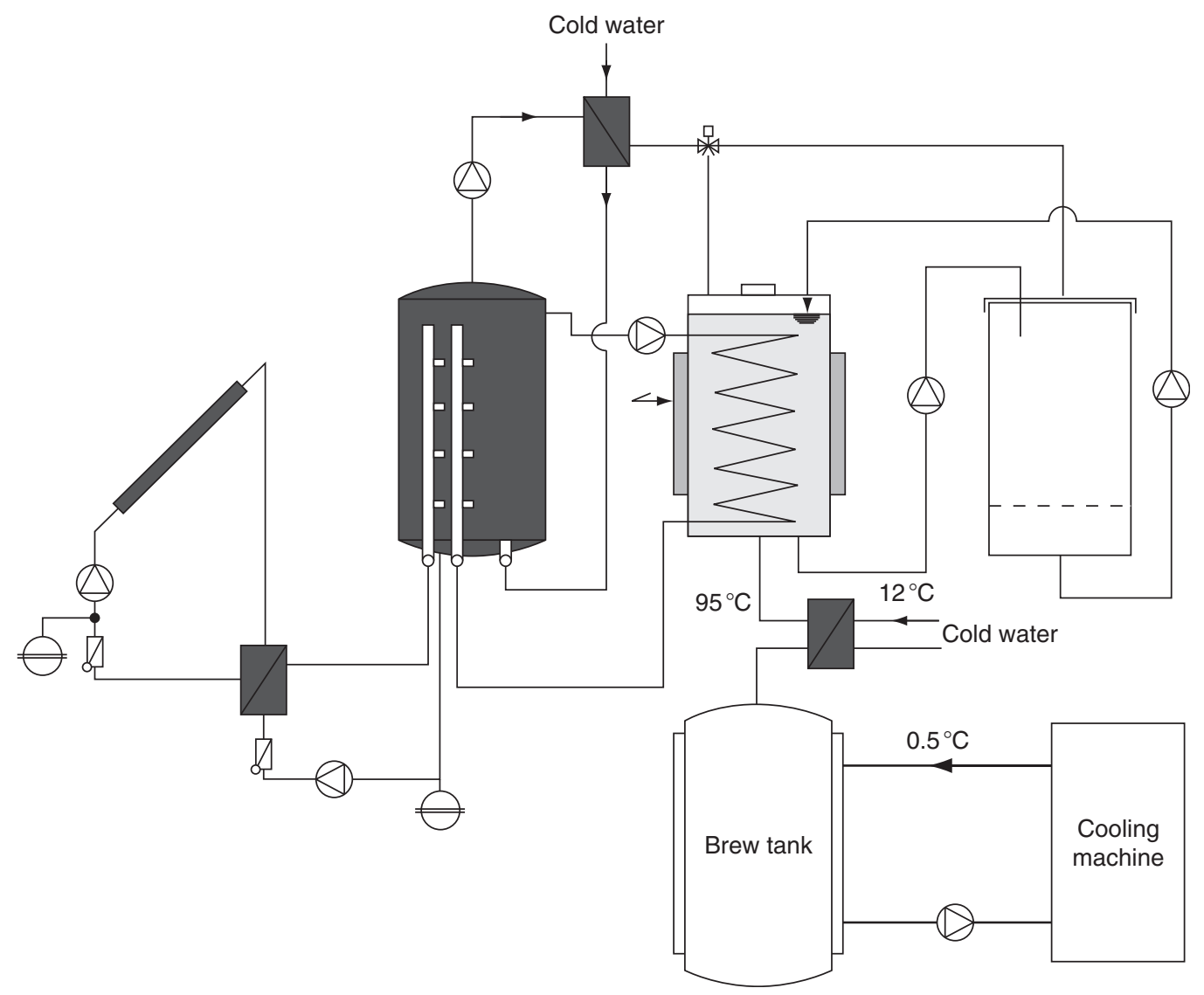

Figure 13 Layout of the Neuwirth solar-heated brewery in Austria.

\subsubsection{Operational Limits}

In solar process heat applications where sensible energy storage is present, it has tended to be both low temperature and low energy density leading to large physical size leading to high initial cost. Water is the preferred sensible heat storage media for which maintaining good outlet discharge temperatures requires thermal stratification [23]. Only occasionally have higher energy density latent or chemical energy storage systems been used: certain types of both the systems are unproven as to the resilience of their energy storage properties after many phase change or chemical reaction cycles, respectively. The use of phase change materials requires careful selection of materials to avoid rapid corrosion [24]. For processes that continue during the night or during periods of insufficient insolation, providing auxiliary heating has been frequently found to be more viable economically than providing sufficient energy storage that would enable solar fractions close to unity to be achieved. An exception is the concomitant solar energy collection and storage provided by a nonconvecting solar pond.

Auxiliary heating is also required where the magnitude and duration of the direct component are insufficient to render feasible a concentrating solar energy collector providing directly the higher application temperatures desired. Flat-plate collectors and evacuated-tube collectors will only provide the temperatures indicated in Figure 2 when the incident insolation has reached a sufficient intensity, and for concentrating collectors the desired outlet temperature is attained only when the direct component of insolation is above a particular intensity. Thus, both the duration of solar-only operation and the range of suitable geographic locations become increasingly limited as the temperature of the application increases. These geographic limitations have been illustrated for flat-plate solar water heating in Europe $[25,26]$, an example of which is shown in Figure 15.

Figure 15 is indicative of the number of days that solar-only operation of a $45^{\circ} \mathrm{C}$ batch process (e.g., washing or low-temperature drying) would be possible using system layouts similar to those shown in Figures 8 and 9 for European locations.

Nonimaging compound parabolic trough medium-temperature solar collectors can exploit a greater part of the available diffuse insolation compared with a parabolic trough collector, although this advantage diminishes as the concentration ratio increases [5].

Many higher temperature industrial processes use steam. Direct steam generation (usually, parabolic trough) solar collectors, intended for electricity production, remove the need to include a heat transfer oil and oil-to-steam heat exchanger when generating steam from a solar thermal system. Again, system control is an important issue; however, the practical limiting factor to the diffusion of this technology is the commercial availability of absorber tubes coated with high-temperature selective surfaces. To reduce costs, the environmental impact of solar energy use in the cement industry has been examined closely. In the dry cement production process, the preliminary partial drying of materials with high moisture content is a promising use of solar energy. 


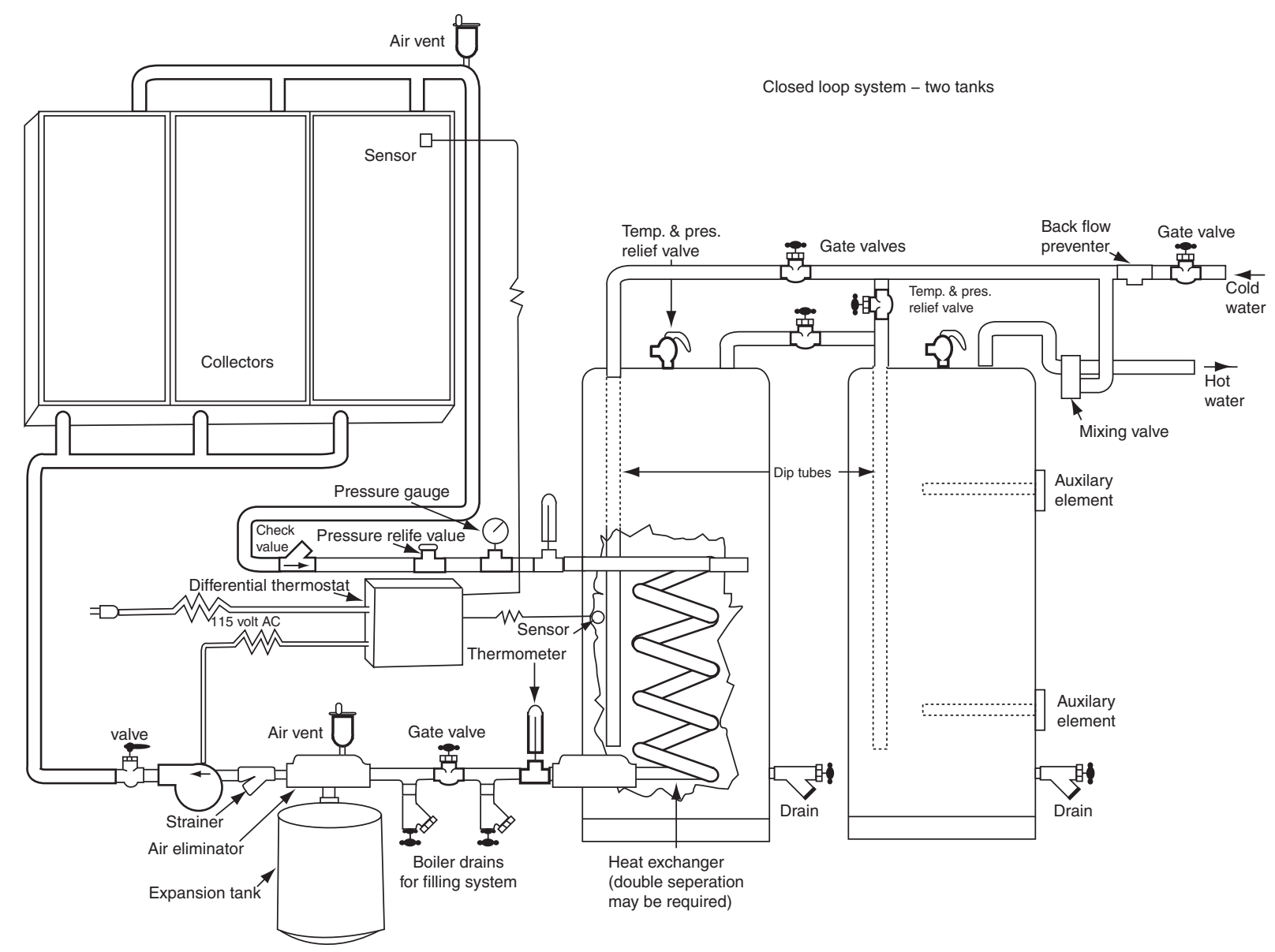

Figure 14 Detailed layout of a closed-loop two-tank system.

To obtain higher temperatures than provided solely by a solar collector, either additional auxiliary heating or thermodynamic conversion is necessary. An example of the latter is heat provided by solar collectors being used to evaporate the working fluid in the evaporator of a heat pump and transfer of heat from a colder reservoir to a warmer reservoir. During the compression, the temperature of the heat pump working fluid increases to well above the temperature provided by the solar collector. During condensation, heat is rejected at a higher temperature to an industrial process heat system or to provide space heating in a glasshouse.

\subsubsection{Solar Hot Water Industrial and Agricultural Process Heat System Design}

\subsubsection{Conceptual Distinctions}

Designing a process heat application that can successfully harness solar energy requires a different conceptual approach from that used typically to design systems that combust fossil fuels. Component sizing and specification together with the choice of control parameters and algorithms have to account for diurnal and annual variations in insolation as well as changes in ambient temperature, humidity, and, in certain circumstances, wind speed. Linked with this, another distinguishing aspect of solar process heating systems is that usually the system control strategy is coupled strongly to collecting the maximum input of solar energy as well as, and often more so than, to satisfying the load. Specifically, a pump or fan for circulating water or air, respectively, through the collector will be activated when a threshold value of insolation is reached that enables the collector to provide a net heat output. In many fossil fuel-heated industrial processes, the control regime seeks to reduce the heat input when the load is satisfied. In contrast, for solar energy systems, discontinuous activations of pumps or fans to maintain an order of precedence of the use of thermal energy first from solar collectors, second from heat stores, and finally from auxiliary heat inputs characterize the control regimes of many solar industrial process heat systems. With the exception of large-scale dryers of high-value products, agricultural systems generally tend to be simpler and thus easier to design, as the process conditions required are often not tightly specified. 


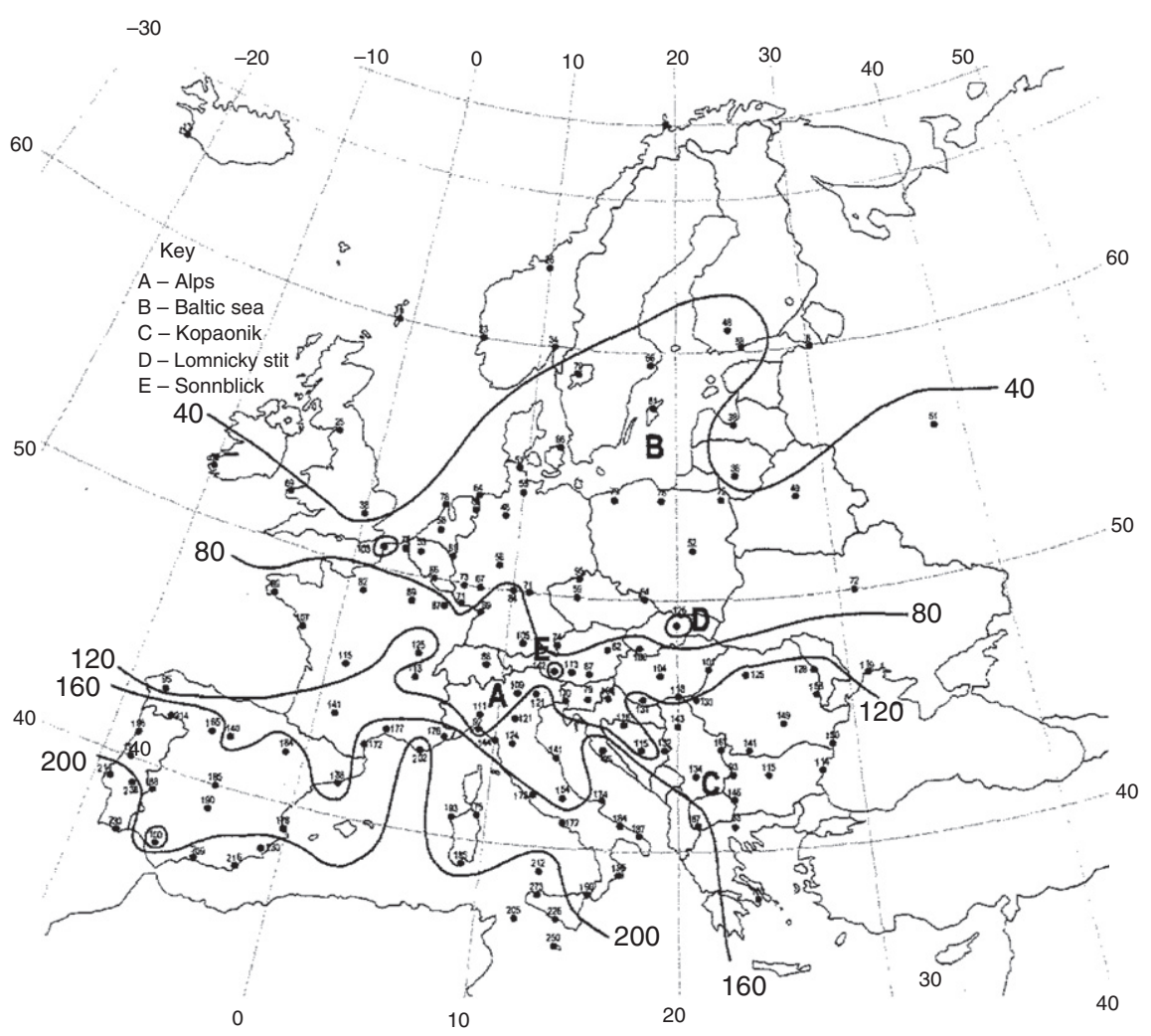

Figure 15 Contour maps of the number of days in a year for which the temperature of solar-heated water in a storage tank reaches or exceeds $45^{\circ} \mathrm{C}$ for Europe [25].

\subsubsection{Design Methodologies}

A wide variety of methodologies are available for the sizing of system components and determining the optimal operating parameters to satisfy a known set of characteristics of the energy load. These methodologies can be classified as utilizability, empirical correlations, simplified analysis, semi-analytical simulation, stochastic simulation, simplified representative-day simulations, and detailed hour-by-hour simulations. Each of these will be considered individually.

Utilizability approaches are based on determining a minimum threshold insolation at which the solar heat gained by a collector corresponds to its heat losses at a particular ambient temperature. Only above this minimum insolation threshold does the collector provide a useful heat output. Utilizability is a statistical property of the location-specific variation of insolation over a given duration. For example, hourly utilizability is the fraction of hourly incident insolation that can be converted to heat by a collector with ideal heat removal and no optical losses. As all solar collectors have heat losses (otherwise, the threshold insolation would always be zero), utilizability always has a value of less than 1 . Utilizability can be related to other statistical properties of diurnal and annual patterns of insolation [27-30] to produce expressions to which specific collector parameters can be attached. Generalized expressions can then be derived, for example, for the yearly total energy delivered by flat-plate collectors whose tilt angles equaled the latitude of their notional location [31]. Although this approach can certainly be useful in initial conceptual and evaluative stages of design, it has inherent limitations. The limitations include (1) the limited accuracy (or otherwise) of underlying insolation data correlations employed, (2) limited portability of design outcome to new locations as utilizability correlations apply to specific locations, particular months and hours within them, and set collector inclinations and orientation, and (3) as only solar collector output is predicted, it should only be applied to industrial and agricultural processes with interseasonal thermal storage where collector inlet temperatures are independent of the very large thermal store mass required [32]. The method has been extended to use two monthly utilizabilities corresponding to those radiation levels that give minimum and maximum operating temperatures [33].

Approaches based on the use of empirical correlations are founded on the reasonable expectation that for a given solar energy process heat system, greater insolation will lead to a larger proportion of the heat load being met by solar energy. Using extensive detailed simulations, design charts have been produced that relate a dimensionless or normalized solar energy input to a similarly parameterized output for a given system configuration, for example the 'F-chart' method [34, 35]. The main drawback of such methods is that accuracy depends on how closely the putative system layout and component specifications correspond with those of the system from which correlations were obtained.

Simplified analyses consider solely the key driving parameters of system performance assuming that all other variables are constant. For solar industrial heat loads that over the operating period have largely constant flow rates and temperatures, 
simplified analyses have been developed that can be employed for feasibility and initial design of industrial hot water systems with heat storage [36] and industrial steam systems [37]. Simplified analyses maintain a logical physical basis for the relationships between parameters that are largely lost in empirical correlations whose equations are of the form of polynominal curve fits.

Semi-analytical simulations use detailed numerical models. However, rather than undertaking hour-by-hour (or similarly discrete time step) calculations using insolation, ambient temperature, and load data, in this approach, sinusoidal and linear functions are usually used to describe the insolation and load, respectively, with ambient temperature either varying sinusoidally or remaining constant. This approach has largely been superseded by hour-by-hour analysis, as the computing resources required to successfully undertake hour-by-hour analysis have become widely available.

A fairly detailed analysis of a representative pressurized hot water solar industrial process system was undertaken to determine curves that define constant solar fractions on graphs of solar collector area against heat storage volume [38]. This approach has been employed to develop a system optimization tool.

In stochastic simulations, Markov chain models are produced to represent insolation, ambient temperature, and load characteristics from hour-by-hour data collected over several years for a specific location. Although long-term system behavior can be determined readily from the transition probability matrices, the method has been rarely, if ever, used in design. Representative-day simulations involve the selection of a meteorologically typical day (or days) within the operating season of the solar industrial or agricultural process heat system. A variety of simulation models may then be employed to determine the outputs of systems with differing layouts, component specifications, and control regimes.

Detailed hour-by-hour simulations are undertaken using mainly well-developed and supported software. The most commonly used solar energy system simulation software is TRNSYS [39] either in its widely available freeware form or as a kernel accessed through a proprietory graphical user interface. It includes ordinary differential and algebraic equations that describe each system component and a differential equation solver. TRNSYS has obtained this ubiquity through (1) its association with authors of one of the seminal textbooks in solar thermal applications [7], (2) its modular structure, which enables easy description of system component interactions via the matching of their respective outputs and inputs via the construction of an information flow diagram, (3) the wide range of component models available, and (4) the fact that should a model for a particular desired component be unavailable, a user can develop a program to simulate that component. The TRNSYS information flow diagram has a similar notional relationship to the actual layout of components as a process flow diagram would have in a chemical engineering process simulation [40]. When appropriate hourly insolation and ambient temperature data and a realistic description of the heat load are available, simulation tools such as TRNSYS can give very accurate predictions of the performance of solar industrial process heat systems. However, to determine the economically optimal combination of system components, many simulations are required. In reality, this use of simulation software is limited to (1) obtaining the final detailed design, (2) developing design correlations, or (3) addressing research issues in systems and components. Artificial intelligence methods have been demonstrated to successfully determine economically optimal designs for a simple, but representative, solar industrial process heat system [41].

\subsubsection{Solar Drying Technologies}

\subsubsection{Solar Drying Processes}

The objective in drying is to reduce the moisture content, usually that of an agricultural product, to a certain level that prevents deterioration within a duration of time regarded as the safe storage period. Drying is the dual process of (1) heat transfer to the product from the heating source and (2) mass transfer of moisture from the interior of the product to its surface and from the surface to the surrounding air. In solar drying, solar energy is used either as the sole source of the required heat or as a supplemental source, and the air flow can be generated by either forced or natural convection. The heating procedure could involve the passage of preheated air through the product, directly exposing the product to solar radiation, or often a combination of both. The major requirement is the transfer of heat to the moist product by convection and conduction from the surrounding air mass at temperatures above that of the product, by radiation mainly from the sun and/or to an extent from the surrounding hot surfaces, or by conduction from heated surfaces in contact with the product. Water starts to vaporize from the surface of the moist product, for example, crop, when the absorbed energy has increased its temperature sufficiently for the water vapor pressure of the crop moisture to exceed the vapor pressure of the surrounding air. The rate of moisture replenishment to the surface by diffusion from the interior depends largely on the nature of the product and its moisture content. If diffusion rate is slow, it becomes the limiting factor in the rate of the drying process, but if it is sufficiently rapid, the controlling factor becomes the rate of evaporation at the product surface. Both the moisture diffusion and convective mass transfer coefficients increase with temperature, although the rate will depend on how the crop is prepared for drying, that is, whether it is peeled and/or sliced. For example, large differences, particularly for convective mass coefficients, have been found between the drying kinetics of cylindrical and sliced potatoes [42]. The solar absorptance of the product is important in direct solar drying; most agricultural materials have relatively high absorptances of between 0.67 and 0.81 . Heat transfer and evaporation rates must be controlled closely for an optimum combination of drying rate and acceptable final product quality.

Examples of 'open-sun' drying are shown in Figure 16. Although widespread, it has inherent limitations: high crop losses can ensue from inadequate drying, fungal attacks, and rodent and insect encroachment. 

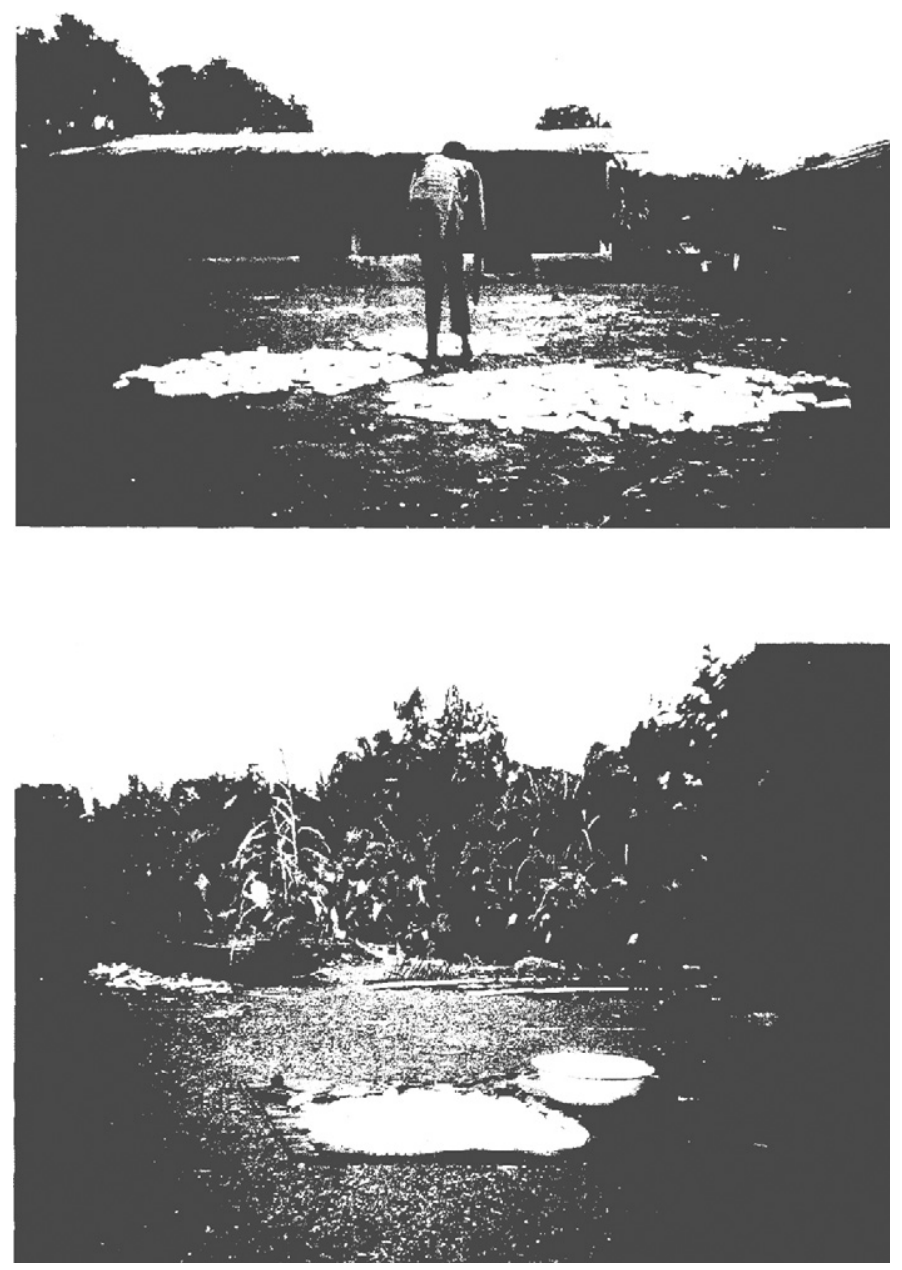

Figure 16 Examples of open-sun drying in Nigeria.

\subsubsection{Solar Dryer Types}

The different types of solar energy crop dryers [43] are classified taxonomically as shown in Figure 17.

The distinguishing features of different types of solar energy dryers are shown in Figure 18.

The advantages of solar dryers over traditional open-sun drying include (1) a smaller area of land in order to dry similar amounts of crop, (2) relatively high quality of dry crop, because insects and rodents are unlikely to infest it during drying, (3) shortened drying period, (4) protection from sudden rain, and (5) low capital and running costs.

Simple integral-type natural circulation solar energy dryers are cheaper to construct than distributed-type solar energy dryers of similar capacity. However, as natural circulation solar energy dryers are liable to localized overheating and show relatively slow overall drying rates, a solar chimney is often employed to provide enhanced buoyant force on the airstream [44], thereby increasing the rate at which dry air enters. Drying times to achieve safe storage moisture content for a variety of tropical crops have been shown experimentally to be reduced by over $20 \%$ when greenhouse drying with a solar chimney is compared to open-air drying under Brazilian conditions [45]. Detailed studies have been undertaken of passive solar dryers incorporating an air heating solar collector, transparent-walled drying chamber, and solar chimney [46].

Cabinet dryers are, usually, relatively small units used typically to preserve domestic quantities of fruits, vegetables, fish, and meat. Solar radiation is transmitted through the cover and is absorbed on the blackened interior surfaces as well as by the product itself. Holes located at both the upper and base of the cabinet's sides allow warmed moist air to leave and replenishing fresh air to be drawn in, respectively, under the action of buoyant forces. Shallow layers of the product are placed on perforated or mesh trays inside the enclosure. Cabinet dryers are almost invariably constructed from materials available locally. As cabinet dryers can exhibit poor air circulation, poor moist air removal results in both slow drying rates and very high internal temperatures of between 70 and 


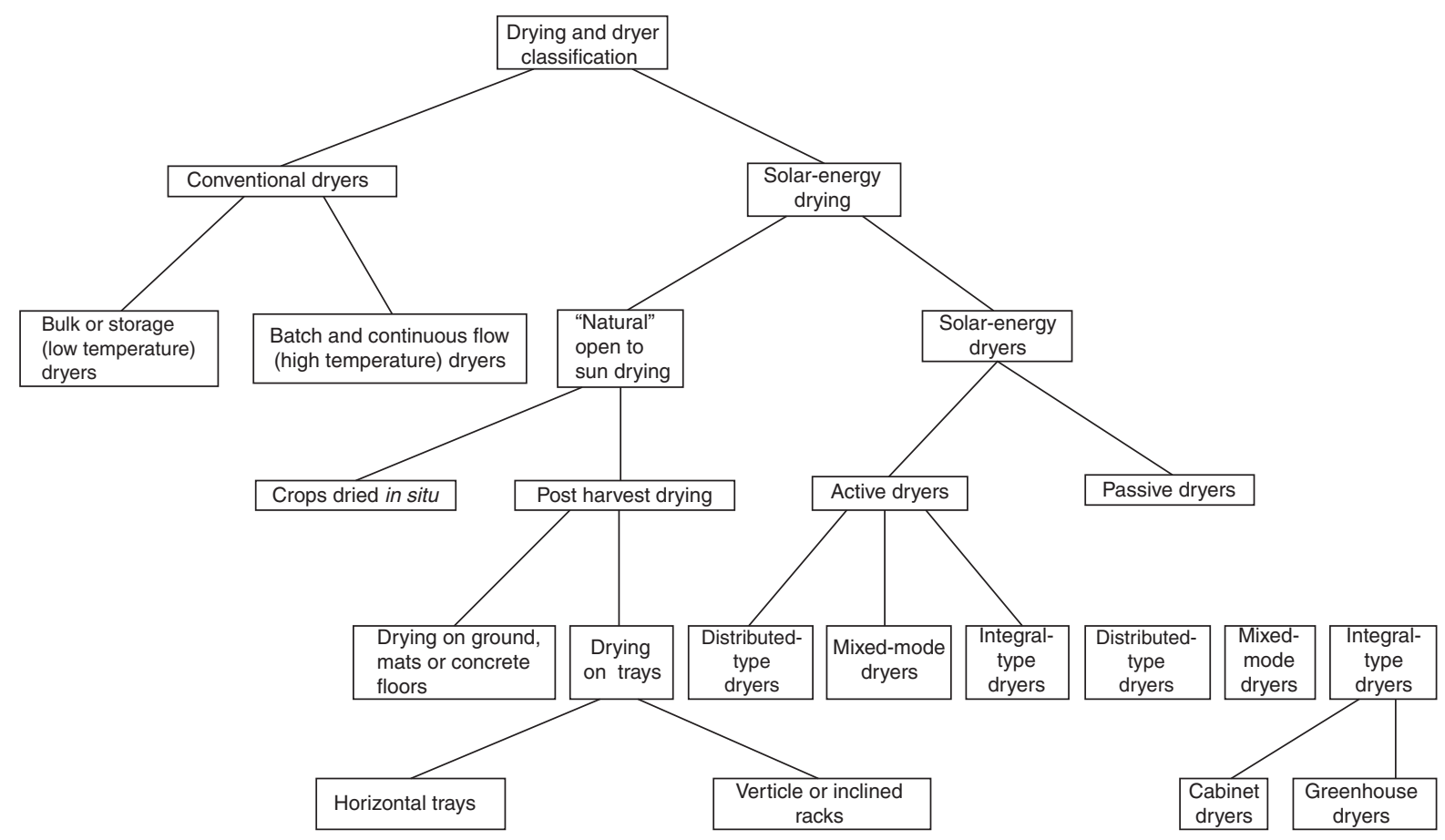

Figure 17 Taxonomy of solar energy dryers.

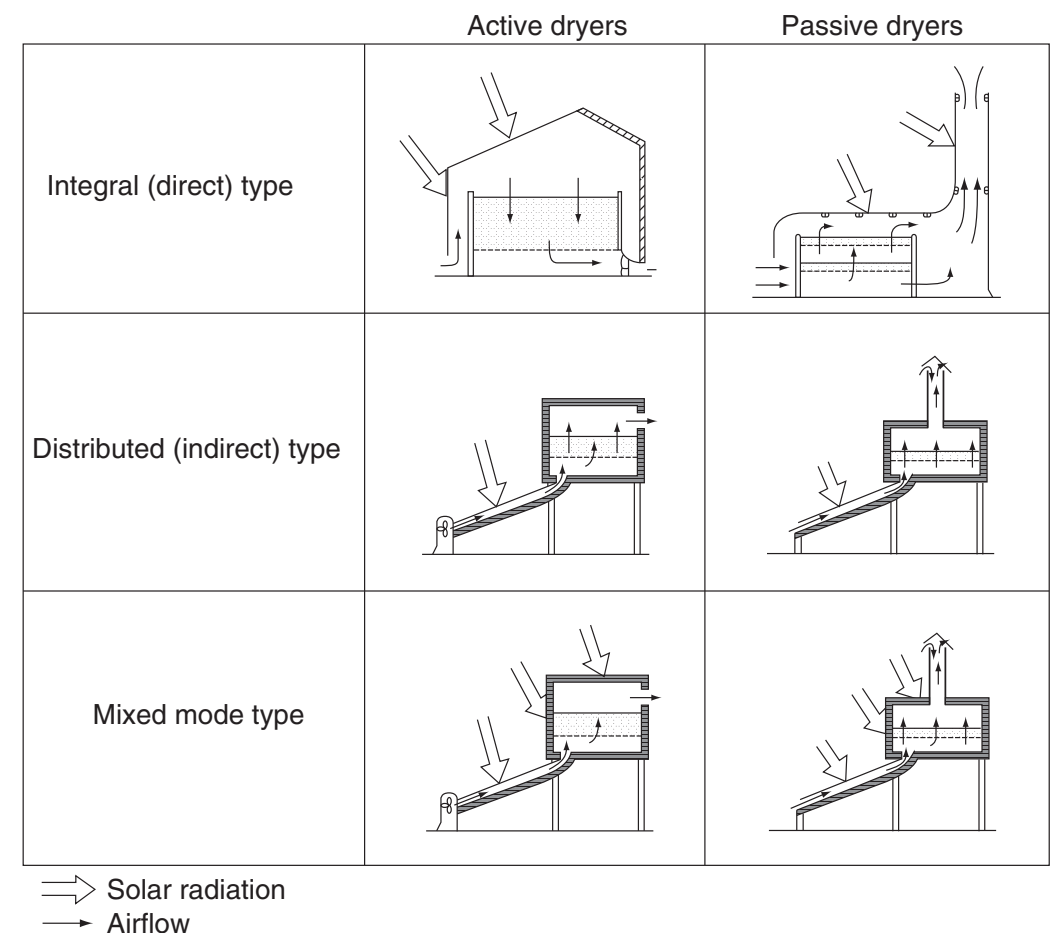

Figure 18 Features of solar energy dryers.

$100{ }^{\circ} \mathrm{C}$, which can spoil perishables, fruits and vegetables, by overheating. Relatively large air inlet and outlet ducts, so as to incur a low pressure drop, together with the addition of a solar chimney are recommended to ensure adequate air circulation.

Natural circulation solar energy greenhouse dryers are larger than most cabinet dryers and are characterized by extensive, usually plastic, glazing on their sides. Insulating panels may be drawn over the glazing at night to reduce heat losses and heat storage may also be provided; although in practice, both these features are rare. A solar greenhouse dryer is more appropriate for large-scale drying, as it gives greater control over the drying process than the solar cabinet dryer. 


\subsubsection{Practical Issues in the Use of Solar Dryers}

The performance of natural circulation solar dryers can be compromised by very high ambient humidity during the wet season [47]: as can be seen in Figure 19, at night the 'dry' air temperature can fall below the prevailing ambient temperature.

This leads, as shown in Figure 20, to relatively moist air being entrained into the dryer and nocturnal reabsorption of moisture by the product.

For crops that require low safe storage moisture contents, drying times can be many days as shown in Figure 21 depending on the dryer's operating temperature.

Direct absorption of solar radiation enhances the proper color 'ripening' of greenish fruits by allowing, during dehydration, the decomposition of residual chlorophyll. For certain varieties of grapes and dates, exposure to sunlight is considered essential for the development of the required color in the dried products. A period of exposure to sunlight of Arabica coffee is thought to give full flavor in the roasted bean. However, insolation entering a process chamber can directly (1) cause different rates of heating due to internal radiant temperature asymmetry and (2) shorten the durability of internal components due to ultraviolet exposure and overheating. For some fruits, exposure to sun reduces the vitamin content considerably. Color retention in some highly pigmented commodities can also be affected adversely by direct exposure to sunlight, although solar tunnel dryers have been used to dry, and retain color in, chillies [48]. The limited concentration of incident insolation provided by reflection from an inclined north wall (at latitude $30.56^{\circ} \mathrm{N}$ ) reduced drying time when drying bitter gourd slices in a greenhouse solar dryer [49]. Greenhouse dryers have employed photovoltaic-powered ventilation [50] and incorporated photovoltaic/thermal collectors [51]. A photovoltaic array has also been employed to power the fan and control systems in dryers with separate air heating solar collectors [52]. Dynamic control is essential if a crop dryer is to achieve the desired process conditions under varying insolation. In solar wood drying, it is necessary to control the interactions of insolation, ambient humidity, wood species characteristics, and variability in the initial moisture content [28, 53].

\subsection{Analysis of solar dryers}

A mathematical model elaborated here follows that developed by Janjai et al. [50] for predicting the performance of a greenhouse dryer. In developing the model, the following were assumed:

1. There is uniformly mixed air inside the dryer.

2. Crop drying behavior can be represented by thin-layer drying correlations.

3. Specific heat capacities of air, cover, ground, and product are constant.

4. The fraction of solar radiation lost through the north wall is negligible and absorptivity of air is negligible.

5. A time interval is employed in the numerical solution of the system of equations that ensures that constant air conditions prevail.

The rate at which energy is stored in the cover is equal to the convective heat energy transfer rate between the air inside the dryer and the cover, plus the rate of radiation heat transfer between the sky and the cover, the thermal convecture heat transfer rate between the cover and ambient air, the radiation heat transfer rate between the crop and the cover, and the rate of solar radiation absorbed by the cover. This energy balance of a greenhouse dryer cover [50] is expressed as

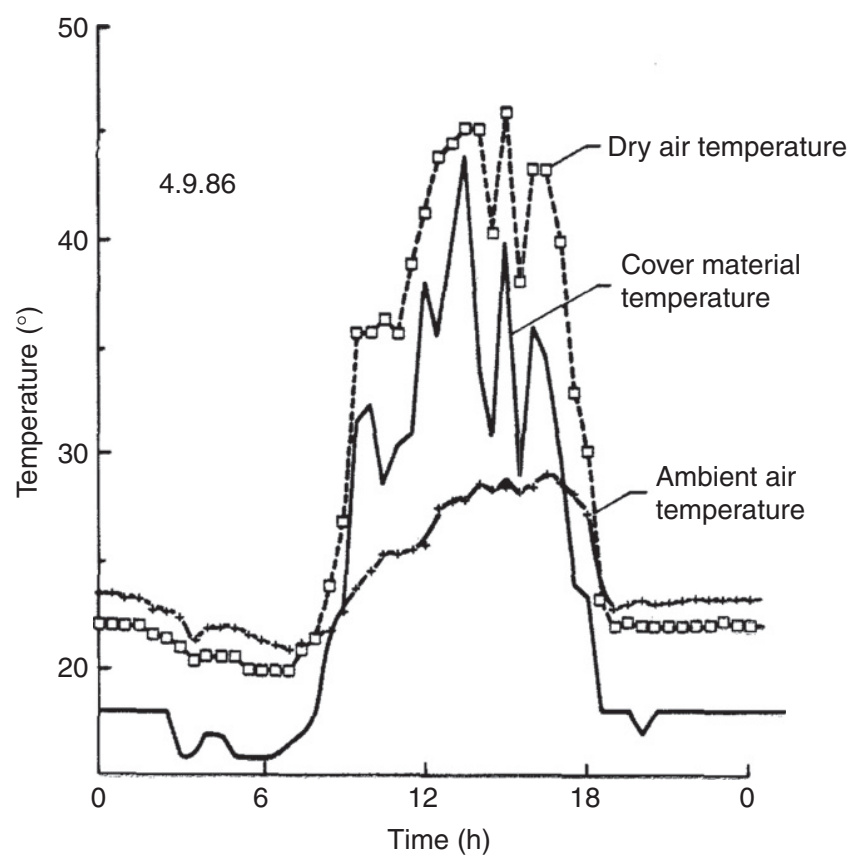

Figure 19 Typical diurnal variation of temperatures in a natural circulation solar dryer in Nigeria in September. 


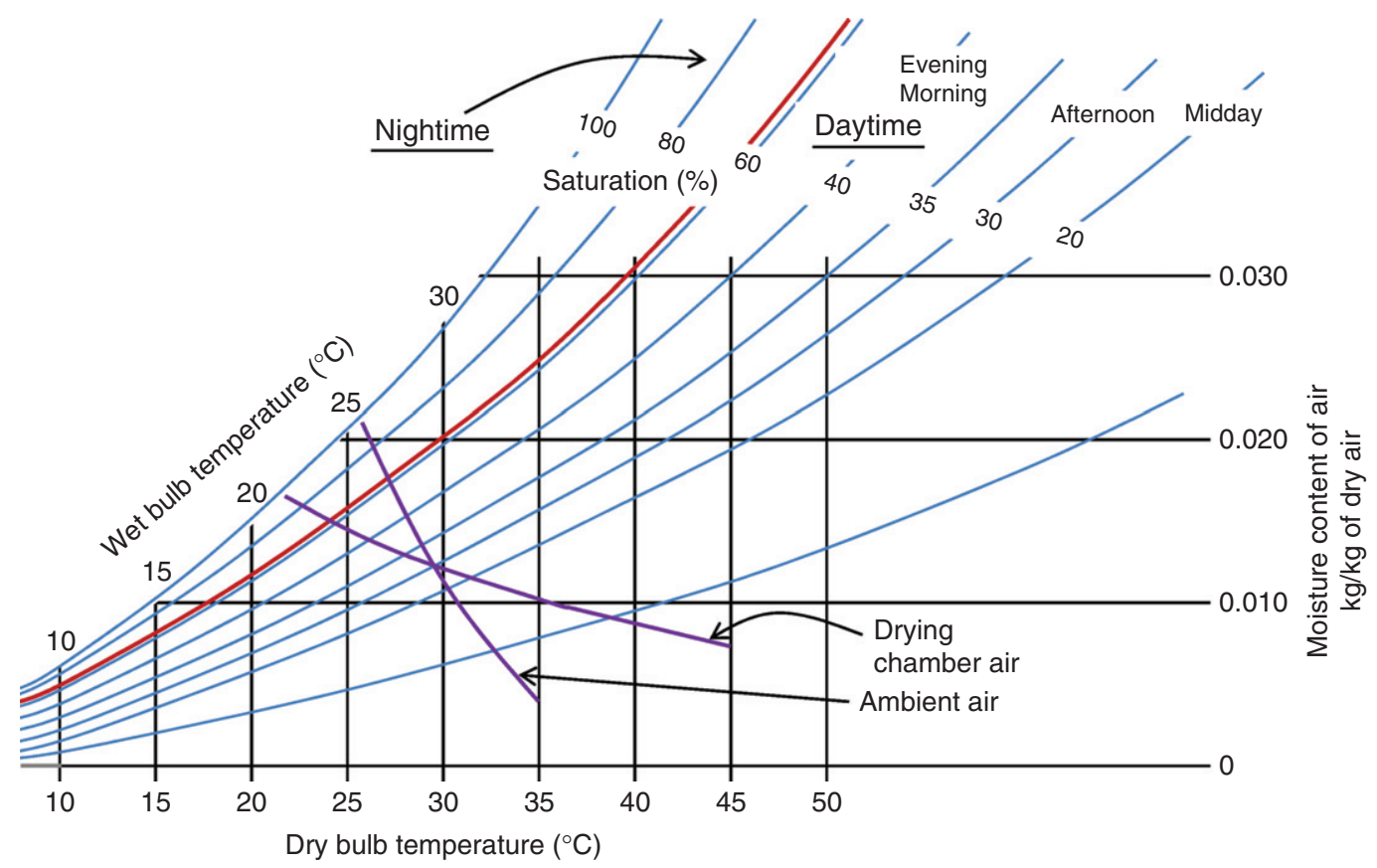

Figure 20 Psychrometric representation of the drying and ambient air for a natural circulation solar dryer in Nigeria.

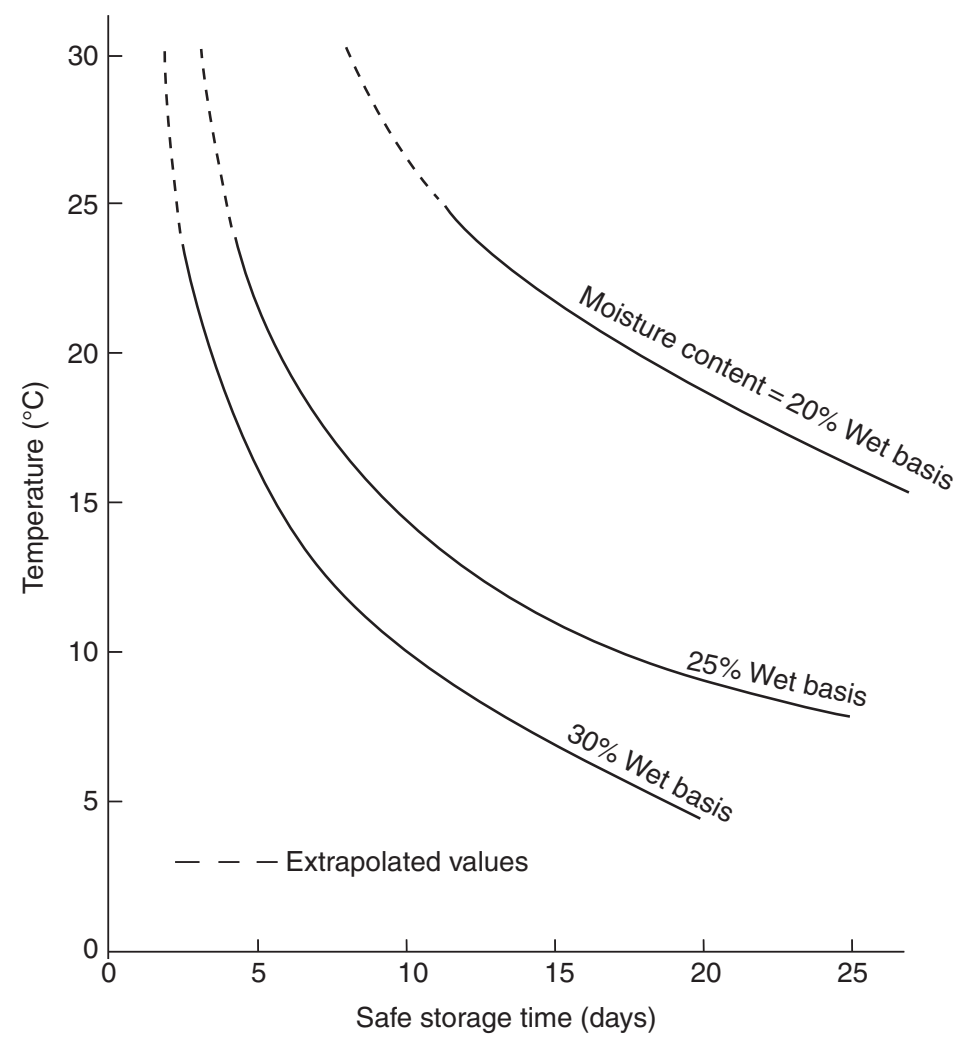

Figure 21 The variation of the drying duration to achieve safe storage with drying temperatures and product moisture contents. 


$$
m_{\mathrm{c}} C_{\mathrm{pc}} \frac{\mathrm{d} T_{\mathrm{c}}}{\mathrm{d} t}=A_{\mathrm{c}} h_{\mathrm{c}, \mathrm{c}-\mathrm{a}}\left(T_{\mathrm{a}}-T_{\mathrm{c}}\right)+A_{\mathrm{c}} h_{\mathrm{r}, \mathrm{c}-\mathrm{s}}\left(T_{\mathrm{s}}-T_{\mathrm{c}}\right)+A_{\mathrm{c}} h_{\mathrm{w}}\left(T_{\mathrm{am}}-T_{\mathrm{c}}\right)+A_{\mathrm{p}} h_{\mathrm{r}, \mathrm{p}-\mathrm{c}}\left(T_{\mathrm{p}}-T_{\mathrm{c}}\right)+A_{\mathrm{c}} \alpha_{\mathrm{c}} I_{\mathrm{t}}
$$

where $C_{\mathrm{pc}}$ is the specific heat capacity of the cover $\left(\mathrm{J} \mathrm{kg}^{-1} \mathrm{~K}^{-1}\right) ; m_{\mathrm{c}}$ is the mass of the cover; $T_{\mathrm{a}}, T_{\mathrm{am}}, T_{\mathrm{c}}$, $T_{\mathrm{p}}$, and $T_{\mathrm{s}}$ are the temperatures $(\mathrm{K})$ of the internal air, ambient, cover, product, and sky, respectively; $A_{\mathrm{c}}$ and $A_{\mathrm{p}}$ are the areas $\left(\mathrm{m}^{2}\right)$ of the cover and product, respectively; $h$ is the relevant heat transfer coefficient $\left(\mathrm{W} \mathrm{m}^{-2} \mathrm{~K}^{-1}\right.$ ) (with radiative heat transfer coefficient, $h_{\mathrm{r}}$, calculated by iteration for the applicable temperature range); $I_{\mathrm{t}}$ is the insolation $\left(\mathrm{W} \mathrm{m}^{-2}\right)$; and $\alpha_{\mathrm{c}}$ is the absorptance of the cover. The energy balance of the air within the layer is equal to the rates of convective heat transfer between the crop and air and floor and air, plus the sensible heat transfer from the crop to air plus the heat associated with flow of air in and out of the dryer taking account of heat loss from air in the layer to ambient and solar energy collected as in eqn [2] where $m_{\mathrm{a}}$ and $C_{\mathrm{pa}}$ are the mass and specific heat of air in $\mathrm{kg}_{\text {and }} \mathrm{kg}^{-1} \mathrm{~K}^{-1}$, respectively; $M_{\rho} \rho, A_{\rho}, D_{\mathrm{p}}, T_{\mathrm{p}}$, and $C_{\mathrm{pp}}$ are the mass, density, area, depth, temperature, and specific heat capacity of the product in $\mathrm{kg}, \mathrm{kg} \mathrm{m}^{-3}, \mathrm{~m}^{2}, \mathrm{~m}, \mathrm{~K}$, and $\mathrm{Jg}^{-1} \mathrm{~K}^{-1}$, respectively; $\alpha_{\mathrm{f}}, A_{\mathrm{f}}$, and $T_{\mathrm{f}}$ apply to the floor; $V_{\text {in }}$ and $V_{\text {out }}$ are the inlet and outlet flow rates $\left(\mathrm{m}^{3} \mathrm{~s}^{-1}\right)$, respectively; and $T_{\text {in }}$ and $T_{\text {out }}$ are the corresponding temperatures $(\mathrm{K})$. $F_{\mathrm{p}}$ is the fraction of insolation incident on the product and $I_{1}$ is the insolation incident.

$$
\begin{aligned}
m_{\mathrm{a}} C_{\mathrm{pa}} \frac{\mathrm{d} T_{\mathrm{a}}}{\mathrm{d} t}= & A_{\mathrm{p}} h_{\mathrm{c}, \mathrm{p}-\mathrm{a}}\left(T_{\mathrm{p}}-T_{\mathrm{a}}\right)+A_{\mathrm{f}} h_{\mathrm{c}, \mathrm{f}-\mathrm{a}}\left(T_{\mathrm{f}}-T_{\mathrm{a}}\right)+A_{\mathrm{p}} D_{\mathrm{p}} C_{\mathrm{pv}} \rho_{\mathrm{p}}\left(T_{\mathrm{p}}-T_{\mathrm{a}}\right) \frac{\mathrm{d} M_{\mathrm{p}}}{\mathrm{d} t} \\
& +\left(\rho_{\mathrm{a}} V_{\text {out }} C_{\mathrm{pa}} T_{\text {out }}-\rho_{\mathrm{a}} V_{\mathrm{in}} C_{\mathrm{pa}} T_{\mathrm{in}}\right)+U_{\mathrm{c}} A_{\mathrm{c}}\left(T_{\mathrm{am}}-T_{\mathrm{a}}\right)+\left[\left(1-F_{\mathrm{\rho}}\right)\left(1-\alpha_{\mathrm{f}}\right)+\left(1-\alpha_{\mathrm{\rho}}\right) F_{\mathrm{\rho}}\right] I_{1} A_{\mathrm{c}} \tau_{\mathrm{c}}
\end{aligned}
$$

The rate at which thermal energy is stored in the crop is equal to the sum of the rate, of thermal energy convective heat transferred to the crop, the rate of thermal energy received from cover by the product due to radiation, the rate of thermal energy lost from the crop due to sensible and latent heat loss from the crop, and the rate of thermal energy absorbed by the crop [50]:

$$
m_{\mathrm{p}}\left(C_{\mathrm{pp}}+C_{\mathrm{pI}} M_{\mathrm{p}}\right) \frac{\mathrm{d} T_{\mathrm{p}}}{\mathrm{d} t}=A_{\mathrm{p}} h_{\mathrm{cp}-\mathrm{a}}\left(T_{\mathrm{a}}-T_{\mathrm{p}}\right)+A_{\mathrm{ph} \tau}, \mathrm{p}-\mathrm{c}\left(T_{\mathrm{c}}-T_{\mathrm{p}}\right)+A_{\mathrm{p}} D_{\mathrm{p}} \rho_{\mathrm{p}}\left[L_{\mathrm{p}}+C_{\mathrm{pv}}\left(T_{\mathrm{p}}-T_{\mathrm{a}}\right)\right] \frac{\mathrm{d} M_{\mathrm{p}}}{\mathrm{d} t}+F_{\mathrm{p}} \alpha_{\mathrm{p}} I_{\mathrm{t}} A_{\mathrm{c}} \tau_{\mathrm{c}}
$$

where $L$ is the latent heat of vaporization of moisture from the product $\left(\mathrm{J} \mathrm{kg}^{-1}\right)$. The conductive heat flow into the floor is equal to the rate of solar radiation absorption on the floor plus the rate of conductive heat transfer between the air and the floor.

$$
-k_{\mathrm{f}} A_{\mathrm{f}} \frac{\mathrm{d} T_{\mathrm{f}}}{\mathrm{d} x}=\left(1-F_{\mathrm{p}}\right) \alpha_{\mathrm{f}} I_{1} A_{\mathrm{c}} \tau_{\mathrm{c}}+A_{\mathrm{f}} h_{\mathrm{c}, \mathrm{f}-\mathrm{a}}\left(T_{\mathrm{a}}-T_{\mathrm{f}}\right)
$$

where $k_{\mathrm{f}}$ is the thermal conductivity of the floor $\left(\mathrm{W} \mathrm{m}^{-1} \mathrm{~K}^{-1}\right)$. The rate of thermal energy flow into the floor due to conduction is

$$
-k_{\mathrm{f}} A_{\mathrm{f}} \frac{\mathrm{d} T_{\mathrm{f}}}{\mathrm{d} x}=A_{\mathrm{f}} h_{\mathrm{d}, \mathrm{f}-\mathrm{g}}\left(T_{\mathrm{f}}-T_{\infty}\right)
$$

where $T_{\infty}$ is the temperature at a depth for which it is interseasonally invariant [54]. The rate of moisture accumulation in the air inside the dryer is equal to the rate of moisture inflow into the dryer due to entry of ambient air minus the rate of moisture outflow from the dryer due to exit of air from the dryer plus the rate of moisture removed from the crop inside the dryer; that is,

$$
\rho_{\mathrm{a}} V \frac{\mathrm{d} H}{\mathrm{~d} t}=\rho_{\mathrm{a}} H_{\text {in }} V_{\text {in }}-\rho_{\mathrm{a}} H_{\text {out }} V_{\text {out }}+A_{\mathrm{p}} D_{\mathrm{p}} \rho_{\mathrm{p}} \frac{\mathrm{d} \mathrm{M}_{\mathrm{p}}}{\mathrm{d} t}
$$

where $H$ is the humidity ratio, with suffixes 'in' and 'out' referring to the dryer inlet and outlet, respectively. The radiative heat transfer coefficient from the cover to the sky $\left(h_{\mathrm{r}, \mathrm{c}-\mathrm{s}}\right)$ is given by [7]

$$
h_{\mathrm{r}, \mathrm{C}-\mathrm{s}}=\varepsilon_{\mathrm{c}} \sigma\left(T_{\mathrm{c}}^{2}+T_{\mathrm{s}}^{2}\right)\left(T_{\mathrm{c}}+T_{\mathrm{s}}\right)
$$

where $\varepsilon_{\mathrm{c}}$ is the emittance of the cover, $\sigma$ is the Stefan-Boltzmann constant $\left(\mathrm{W} \mathrm{m}^{-2} \mathrm{~K}^{-4}\right)$. Radiative heat transfer coefficient between the crop and the cover $\left(h_{\mathrm{r}, \mathrm{p}-\mathrm{c}}\right)$ is given by [7]

$$
h_{\mathrm{r}, \mathrm{p}-\mathrm{c}}=\varepsilon_{\mathrm{p}} \sigma\left(T_{\mathrm{p}}^{2}+T_{\mathrm{c}}^{2}\right)\left(T_{\mathrm{p}}+T_{\mathrm{c}}\right)
$$

where $\varepsilon_{\mathrm{p}}$ is the emittance of the crop. As $\left(h_{\mathrm{r}, \mathrm{c}-\mathrm{s}}\right)$ and $\left(h_{\mathrm{r}, \mathrm{p}-\mathrm{c}}\right)$ are functions of temperature, these are computed iteratively at each time during a simulation. The sky temperature $\left(T_{\mathrm{s}}\right)$ is

$$
T_{\mathrm{s}}=0.552 T_{\mathrm{am}}^{1.5}
$$

Convective heat transfer coefficient from the cover to ambient due to wind $h_{\mathrm{w}}$ is [7]

$$
h_{\mathrm{w}}=5.7+3.8 V_{\mathrm{w}}
$$

Convective heat transfer coefficient inside the solar greenhouse dryer for either the cover or product and floor $\left(h_{c}\right)$ is computed from

$$
h_{\mathrm{c}, \mathrm{f}-\mathrm{a}}=h_{\mathrm{c}, \mathrm{c}-\mathrm{a}}=h_{\mathrm{c}, \mathrm{p}-\mathrm{a}}=h_{\mathrm{c}}=\frac{\mathrm{Nu} k_{\mathrm{a}}}{D_{\mathrm{h}}}
$$


where $D_{\mathrm{h}}$ is given by

$$
D_{\mathrm{h}}=\frac{4 W D}{2(W+D)}
$$

where $W$ and $D$ are the width and height of the dryer (m), respectively, and the Nusselt number is

$$
\mathrm{Nu}=0.0158 \mathrm{Re}^{0.8}, \quad \text { Re is the Reynolds number, } \quad \mathrm{Re}=\frac{D_{\mathrm{h}} V_{\mathrm{a}}}{v_{\mathrm{a}}}
$$

where $V_{\mathrm{a}}$ is the air speed in the dryer and $v_{\mathrm{a}}$ is the kinematic viscosity of air. The overall heat loss coefficient from the greenhouse dryer cover $\left(U_{\mathrm{c}}\right)$ is computed from

$$
U_{\mathrm{c}}=\frac{k_{\mathrm{c}}}{\delta_{\mathrm{c}}}
$$

where $k_{\mathrm{c}}$ and $\delta_{\mathrm{c}}$ are the thermal conductivity $\left(\mathrm{W} \mathrm{m}^{-1} \mathrm{~K}^{-1}\right)$ and the thickness $(\mathrm{m})$ of the cover, respectively. form

Thin-layer drying correlations are obtained for particular crops by determining experimentally the best fit to an equation of the

$$
\frac{M(t)-M_{e}}{M_{\mathrm{o}}-M_{\mathrm{l}}}=X \exp \left(-Y t^{Z}\right)
$$

where $M(t), M_{\mathrm{o}}$, and $M_{\mathrm{e}}$ are the moisture contents (as percentage of dry bulb) at time $t$, originally, and at equilibrium respectively. $X$, $Y$, and $Z$ are constants. Different values for $X, Y$, and $Z$ are found for different crops and often for different methods of crop preparation before drying. For example, for peeled longan (in a single layer), the following thin-layer drying correlation has been obtained [50]:

$$
\frac{M-M_{e}}{M_{\mathrm{o}}-M_{\mathrm{e}}}=\exp \left(A_{1} t^{\beta_{1}}\right)
$$

where

$$
\begin{aligned}
& A_{1}=-0.213788+0.0101640 T-0.00137 \mathrm{rh} \\
& B_{1}=1.108816-0.0005210 T-0.000061 \mathrm{rh}
\end{aligned}
$$

where $T$ is the air temperature in ${ }^{\circ} \mathrm{C}$ and $\mathrm{rh}$ is the relative humidity expressed as a percentage.

For banana, the thin-layer drying correlation

$$
\frac{M-M_{e}}{M_{\mathrm{o}}-M_{\mathrm{e}}}=A_{2} \exp \left(-B_{2}^{t}\right)
$$

has been obtained [55] where

$$
\begin{aligned}
& A_{2}=1.503574+0.00505455 \mathrm{rh}-0.01327 T-0.00021417 \mathrm{rh}^{2}+0.000094 T^{2} \\
& B_{2}=0.1874+0.00193 \mathrm{rh}-0.00635 T-0.00007978 \mathrm{rh}^{2}+0.00081 T^{2}
\end{aligned}
$$

Similarly, empirically derived equations have been determined experimentally for equilibrium moisture content $\left(M_{\mathrm{e}} \% \mathrm{db}\right)$ of crops; for peeled longan [50], this is

$$
a_{\mathrm{w}}=\frac{1}{1+\left[\frac{b_{\mathrm{o}}+b_{1} T}{M_{\mathrm{e}}}\right]^{b_{2}}}
$$

where $a_{\mathrm{w}}$ is the water activity, $b_{\mathrm{o}}=79.9826, b_{1}=-0.8277$, and $b_{2}=2.1867$, and for banana this is [55]

$$
M_{\mathrm{e}}=74.66023=1.144253 T+37.07224 a_{\mathrm{w}}+0.001166 T^{2}+51.55374 a_{\mathrm{w}}^{2}
$$

\subsubsection{Solar Furnaces}

Solar materials processing involves effecting the chemical conversion of materials by their direct exposure to concentrated solar energy. Solar furnaces can reach higher temperatures (up to $3800^{\circ} \mathrm{C}$ ) than combustion or electric furnaces and avoid product contamination from the carbon electrodes of the latter. A diverse range of approaches are being researched for applications related to high-added-value products such as fullerenes, large carbon molecules with major potential commercial applications in 


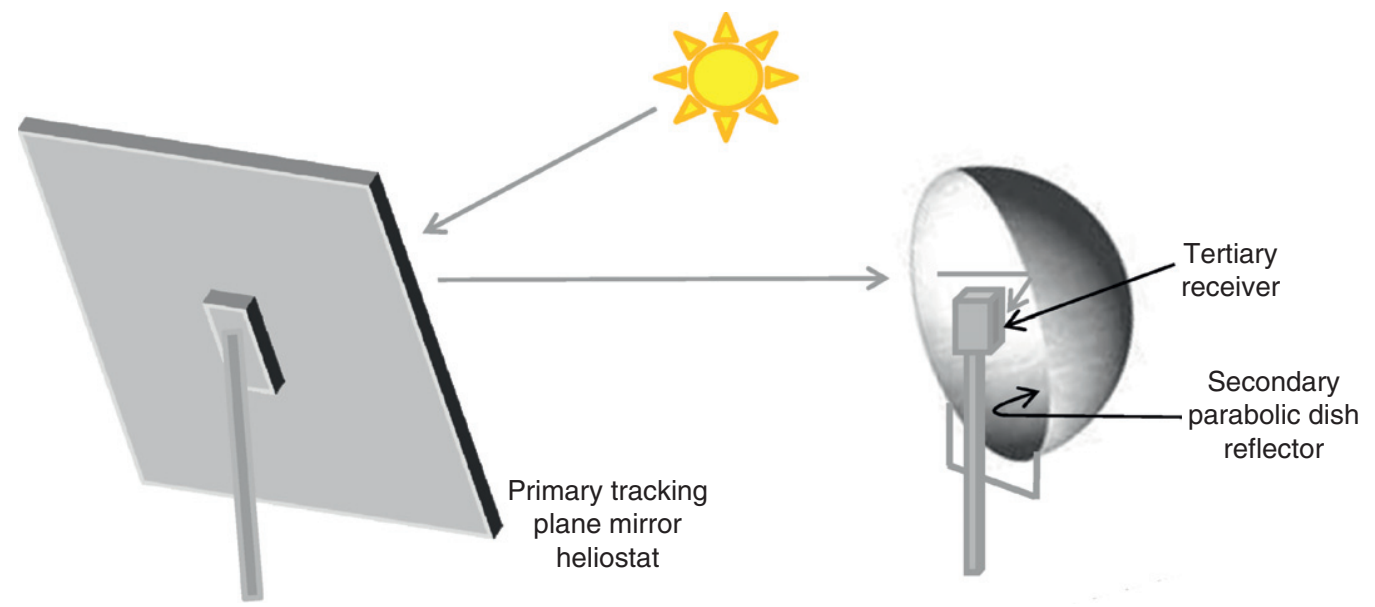

Figure 22 A solar furnace [57].

semiconductors and superconductors, to commodity products such as cement. None of these processes have achieved mainstream commercial adoption.

A solar furnace such as that shown in Figure 22 can create a concentrated beam with intensity that is tens of thousands times the initial solar intensity. The surface of a material will be heated extremely rapidly when exposed to such a beam; the short heat pulse is dissipated largely by radiative heat transfer to the surroundings, avoiding heating the underlying substrate. Such rapid surface heating is necessary for chemical vapor deposition and ceramic metallization. In the latter, concentrated insolation can be used to bond thin layers of metal to a ceramic substrate to manufacture high-quality electronic components. Producing fullerenes in a solar furnace would use less energy than conventional production technologies. Solar-pumped lasers operate in the same manner as conventional lasers but use concentrated insolation for power instead of electricity. Potential applications include specialized materials processing and photochemistry. At a temperature of $1780{ }^{\circ} \mathrm{C}$ and $u$ nder a $\mathrm{N}_{2}-\mathrm{H}_{2}$ atmosphere, grain growth and density increase have ensued after sintering alumina powder in a solar furnace located at the focus of a heliostat field [56].

\subsubsection{Greenhouses}

\subsubsection{Achieving a Desired Interior Microclimate}

A greenhouse is an enclosure designed to help create and maintain a suitable environment for enhancing the rates of growth of plants $[58,59]$. These requirements vary according to the particular plant species and its stage of growth, and the approach to creating a specified environment depends on the prevailing ambient conditions and the value of the crop when harvested. The plant varieties chosen to be grown should suit the optimal artificial greenhouse environment that can be achieved economically. Multispan metal-framed modular greenhouses are the most prevalent commercially used form. Cheap Quonset-shaped 'polytunnels' and the less-common air-supported greenhouses, which utilize a lightweight transparent plastic film as the cover material, have been developed. Short-wave insolation transmitted through a greenhouse cover is absorbed by internal surfaces. These surfaces reemit longer wavelength radiation, to which the cover, traditionally of glass, is relatively opaque. The rate of heat loss from a polyethylene-covered greenhouse is thus $10-15 \%$ higher than from a similar glass greenhouse: when the cover is dry, this difference can be attributed largely to the transparency of polyethylene to long-wave radiation. Radiation trapping typically contributes only $10-25 \%$ of the total 'greenhouse effect', rather it is the suppression of convection losses by the presence of the enclosure itself that is usually the major cause of daytime temperature rises inside most greenhouses. The influences on the interior microclimate of a greenhouse can be categorized as shown in Table 2.

Heat losses may be reduced by the use of multiple-paned greenhouses and/or the nocturnal deployment of insulating screens [60,61]. The ground temperature at a depth of about $1 \mathrm{~m}$ remains fairly constant throughout the year [54]. In suitable climates, fluid conveyed through the ground at this depth can be used to cool a greenhouse in summer and heat it in winter [62-64].

\subsubsection{Greenhouse Heating and Cooling}

The main source of heat for any greenhouse should be direct insolation. However, most greenhouses use supplementary heating systems for periods when solar heating is insufficient [65]. Heat storage is less frequently used although an air heating solar collector used to preheat air can readily be coupled with a rockpile to provide a sensible heat store. Such a system is particularly useful where daytime insolation levels are high and, due to nocturnal radiative cooling, the subsequent nights are cold. The ground itself can also 


\begin{tabular}{|c|c|c|c|}
\hline $\begin{array}{l}\text { Greenhouse microclimatic } \\
\text { characteristics }\end{array}$ & $\begin{array}{l}\text { Ambient climatic } \\
\text { parameters }\end{array}$ & Structural parameters & Operational parameters \\
\hline \multirow[t]{2}{*}{ Temperature } & Air temperature & $\begin{array}{l}\text { Transmittance of cover to insolation and } \\
\text { long-wave thermal radiation }\end{array}$ & Ventilation rate \\
\hline & $\begin{array}{l}\text { Wind speed } \\
\text { Insolation }\end{array}$ & $\begin{array}{l}\text { Thermal storage and heat-transmission properties } \\
\text { of greenhouse }\end{array}$ & $\begin{array}{l}\text { Heating and cooling systems } \\
\text { Presence of shades and } \\
\text { thermal screens }\end{array}$ \\
\hline $\begin{array}{l}\text { Photosynthetically active } \\
\text { radiation intensity }\end{array}$ & Insolation & $\begin{array}{l}\text { Photosynthetically active radiation transmittance } \\
\text { Obstruction by opaque structural framework }\end{array}$ & $\begin{array}{l}\text { Presence of shades } \\
\text { Supplementary lighting }\end{array}$ \\
\hline Atmospheric constituents & $\begin{array}{l}\text { Levels of humidity, } \mathrm{CO}_{2} \\
\mathrm{NO}_{x}, \mathrm{SO}_{2}\end{array}$ & Air tightness of the structure & $\begin{array}{l}\text { Ventilation rate } \\
\text { Humidity control } \\
\mathrm{CO}_{2} \text { supplementation }\end{array}$ \\
\hline
\end{tabular}

be used for heat storage by ducting warm exhaust air from the greenhouse under the ground's surface [66]. Solar ponds have also been used for greenhouse heating.

In temperate climates, greenhouse cooling is achieved by increasing the rate of ventilation by opening ridge vents in conventional rigid-structured greenhouses to provide wind-induced and buoyancy-driven ventilation. On hot, calm days, fan-assisted ventilation is often used. On days of very high insolation, ventilation rates of over 60 air changes per hour may be necessary. Evaporative cooling techniques are often used in greenhouses, by either (1) directly wetting the air inside the greenhouse or (2) wetting the ground surface or the external cover of the greenhouse. A wide range of heating, cooling, and energy storage technologies are available for use in greenhouses $[67,68]$. To reduce high solar gains, shades should be fitted externally, rather than internally, to reject their absorbed heat to the ambient environment. The use of an insulating glazing material that becomes opaque during periods of high insolation is technologically feasible, although currently not commercially viable [69].

\subsubsection{Heating and Ventilation of Industrial and Agricultural Buildings}

\subsubsection{Solar Air Heating}

Solar energy may be used for the space heating of agricultural buildings. The guiding economic principles are to first conserve energy, then adopt passive means of solar energy collection, distribution, and storage, and only then consider active solar technologies. The use of active solar technologies has been aided where the construction of farm building roofs can be modified readily to house air heating solar collectors. Low-cost roof-based air heating solar collectors are fabricated either from a transparent plastic film cover over a black plastic or metal absorber or from metal with glass covers. Farm-built metal solar air heaters range from unglazed low-temperature units for animal husbandry through to double-glazed medium-temperature systems for crop drying [8]. The principal attractions of farm-built roof-mounted air heating collectors are the low initial investment required giving low-cost availability of heated air for drying [70]. The disadvantages are that potentially suboptimal design of system components and poor fabrication quality lead to poor performance.

When a roof-space collector is formed by glazing the south-facing slope of a pitched roof, it enables the passive collection and active distribution of solar heat. Warmth is stored, to some extent, within the structural members of the roof-space collector. A roof-space collector can have a low initial capital cost as its physical construction may not differ greatly from that of a conventional pitched roof. In addition, a reduction in additional cost can arise when a roof-space collector is a preheater from the employment of components (i.e., fans and controls) that would be already present in an auxiliary air heating system.

Isolated gain collectors such as the thermosiphoning air panel [71] and transpired collectors overcome some of the disadvantages of indirect gain collectors by dispensing with heat storage and relying totally on convective heat gain. Heat input is almost immediate, while heat losses during nongain periods when the collector is isolated from the heated space are low. This design is suited to providing daytime heating in cool or cold climates. A thermosiphoning air panel operates in the same manner as the natural convection mode of a Trombe-Michel wall. However, the absorber is often made of metal, usually aluminum or steel, and the unit is insulated to prevent heat loss to, or from, the building. Heat output from a thermosiphoning air panel is controlled by full or partial manual closure of an inlet or existing vent.

\subsubsection{Direct Solar Gain and Thermal Mass}

Successful solar energy use is reconciled harmoniously with the diverse set of physical constraints (e.g., site and internal arrangement) and functional requirements (e.g., structure and use) that a particular industrial and agricultural building must satisfy. The immediate effect of direct solar gain can be ameliorated by thermal mass acting at different times as (1) primary mass is the wall and floor surfaces (masonry features or elements containing water or a phase change material) insolated directly by diurnal sun patch 
motion across the floor and the lower zones of the walls, (2) secondary mass irradiated by diffuse and reflected insolation and long-wave thermal radiation from directly insolated, primary mass surfaces, and (3) tertiary mass to which heat is transferred by solar heated air. For efficient overall operation, the auxiliary heating system must respond readily both to provide heating when the direct solar gains to particular zones cease and to switch off when solar gains resume.

\subsubsection{Solar Cooking}

\subsubsection{Types of Solar Cooker}

A classification of solar cookers is shown in Figure 23. In focusing cookers, a solar energy concentrator directs solar radiation on to a focal area at which the cooking vessel is located. In these cookers, the convection heat loss from the cooking vessel is large and the cooker utilizes only the direct solar radiation. Hot-box cookers consist of an insulated box painted black internally and double glazed. To enhance solar gain, plane sheet reflectors (single or multiple) may be employed. The adjustment of the cooker toward the sun is not required as frequently as in the case of focusing-type solar cookers. In most hot-box cookers, cooking can take a long time and many dishes cannot be prepared with this cooker as, depending on the weather, temperatures only in the range $50-80{ }^{\circ} \mathrm{C}$ are achieved. With indirect cookers, the problem of cooking outdoors is avoided as the solar heat is transferred directly to the cooking vessel in the kitchen. The cookers use either a flat-plate or focusing collector [72] from which collected solar heat is transferred to the cooking vessel. Methods for the design and characterization of solar cookers have been developed [73, 74]. Solar cooking has been advocated in many rural developing country contexts as a means of avoiding the use of wood for fuel, thereby limiting further deforestation and land erosion.

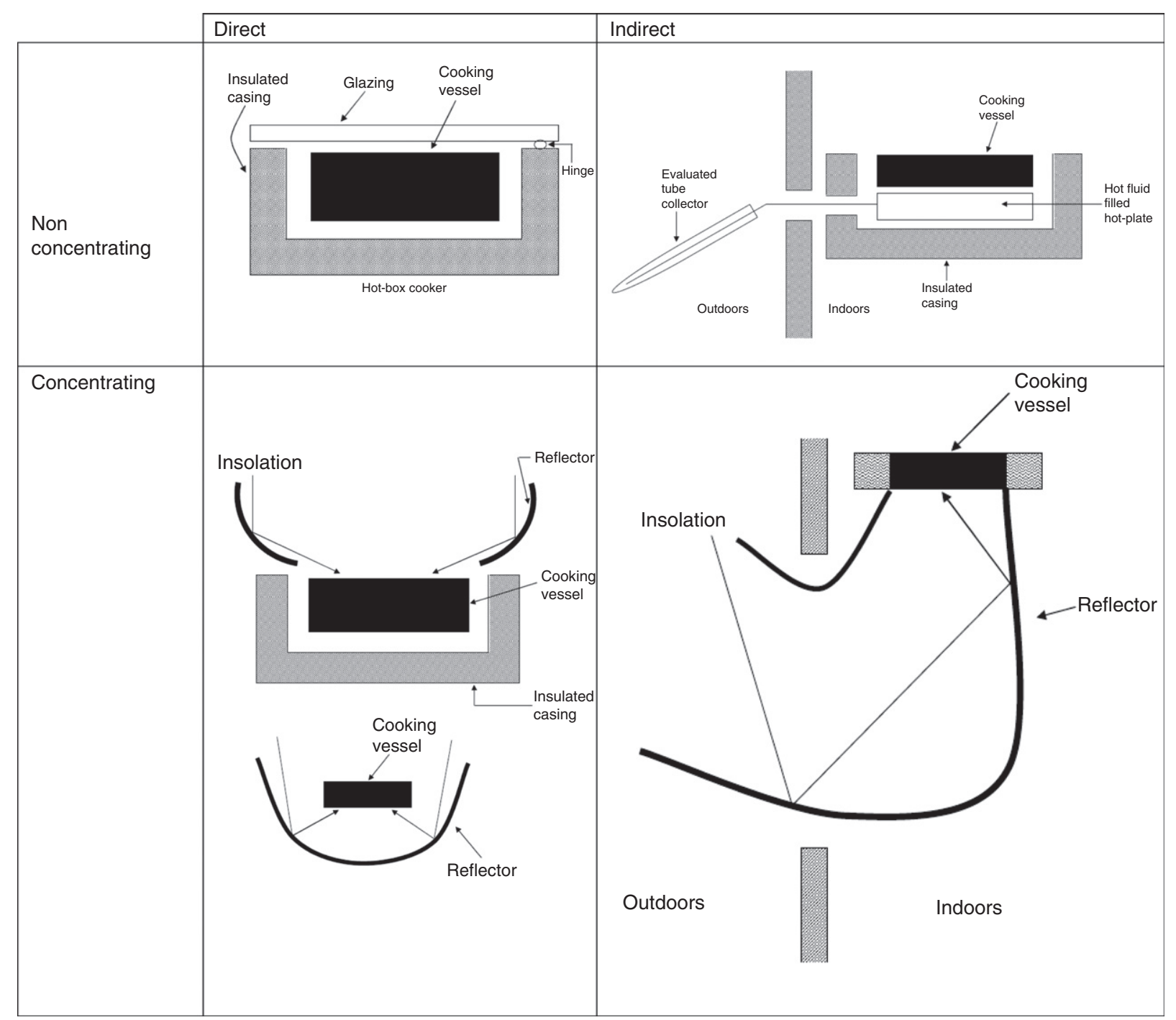

Figure 23 Classification of solar cookers. 


\subsubsection{Analysis of Solar Cookers}

An energy balance of a simple solar cooker is [73]

$$
m c_{\mathrm{p}} \frac{\mathrm{d}\left(T_{\mathrm{p}}-T_{\mathrm{a}}\right)}{\mathrm{d} t}=\left\{\eta_{\mathrm{o}} I-U\left(T_{\mathrm{p}}-T_{\mathrm{a}}\right)\right\} A
$$

where $m$ is the mass of the pot $(\mathrm{kg}), c_{\mathrm{p}}$ is the specific heat capacity at constant pressure $\left(\mathrm{J} \mathrm{kg}^{-1} \mathrm{~K}^{-1}\right),\left(T_{\mathrm{p}}-T_{\mathrm{a}}\right)$ is the temperature difference between the temperature of the pot content and the ambient temperature $(\mathrm{K}), \eta_{\mathrm{o}}$ is the optical efficiency, $I$ is the global solar radiation $\left(\mathrm{W} \mathrm{m}^{2}\right), U$ is the overall heat loss coefficient $\left(\mathrm{W} \mathrm{m}^{-2} \mathrm{~K}^{-1}\right)$, and $A$ is the aperture area $\left(\mathrm{m}^{2}\right)$. The temperature rise above ambient at time $t$ is thus given by

$$
\left(T_{\mathrm{p}}-T_{\mathrm{a}}\right)_{t}=m\left(1-\mathrm{e}^{-I A t / m c}\right)
$$

Under conditions of constant insolation, the overall heat loss coefficient can be calculated from a heat loss test [73] as

$$
U=\frac{m c_{\mathrm{p}}}{t_{\text {end }}-t_{\text {start }}} \ln \frac{\left(T_{\mathrm{p}}-T_{\mathrm{a}}\right)_{\text {start }}}{\left(T_{\mathrm{p}}-T_{\mathrm{a}}\right)_{\text {out }}}
$$

where $t_{\text {start }}$ and $t_{\text {end }}$ are the times (in seconds) the test commenced and concluded, respectively. Alternatively, the overall heat loss coefficient can be determined for stagnation conditions under constant insolation from

$$
U=\frac{\eta_{\mathrm{o}} I}{T_{\mathrm{stag}}}
$$

\subsubsection{Solar Desalination}

\subsubsection{Solar Desalination Systems}

Pollution of the rivers and lakes by industrial effluents and sewage has made freshwater scarce in parts of the third world and is becoming the single largest cause of freshwater shortages. About $79 \%$ of water available on the earth is salty, $20 \%$ is brackish, and only $1 \%$ is fresh. Many diseases are caused by unhygienic drinking water [75]. Over 2000 million people do not have ready access to an adequate supply of safe water. Conventional distillation plants are intensive users of fossil fuel energy. Many arid regions have underground brackish water resources or are close to seawater and have high annual levels of insolation. The production of potable water using solar energy has thus been well researched [76, 77] and in remote or isolated regions has been adopted practically. Among the most common solar desalination systems are (1) basin solar still shown in Figure 24, (2) multistage flush evaporation [77] shown in Figure 25, (3) reverse osmosis shown in Figure 26, and (4) multieffect evaporation shown in Figure 27.

Potable water extraction processes using solar energy include (1) passive solar stills and (2) multistage flash evaporation shown in Figure 22.

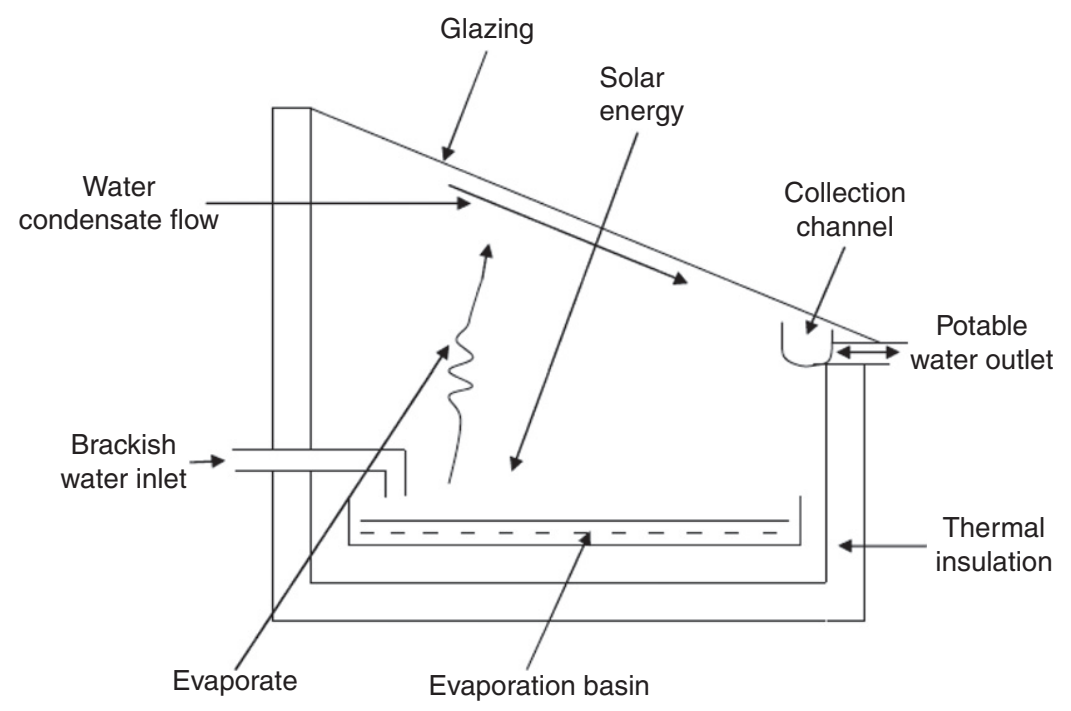

Figure 24 A single-slope basin solar still. 
Flash and heat recovery

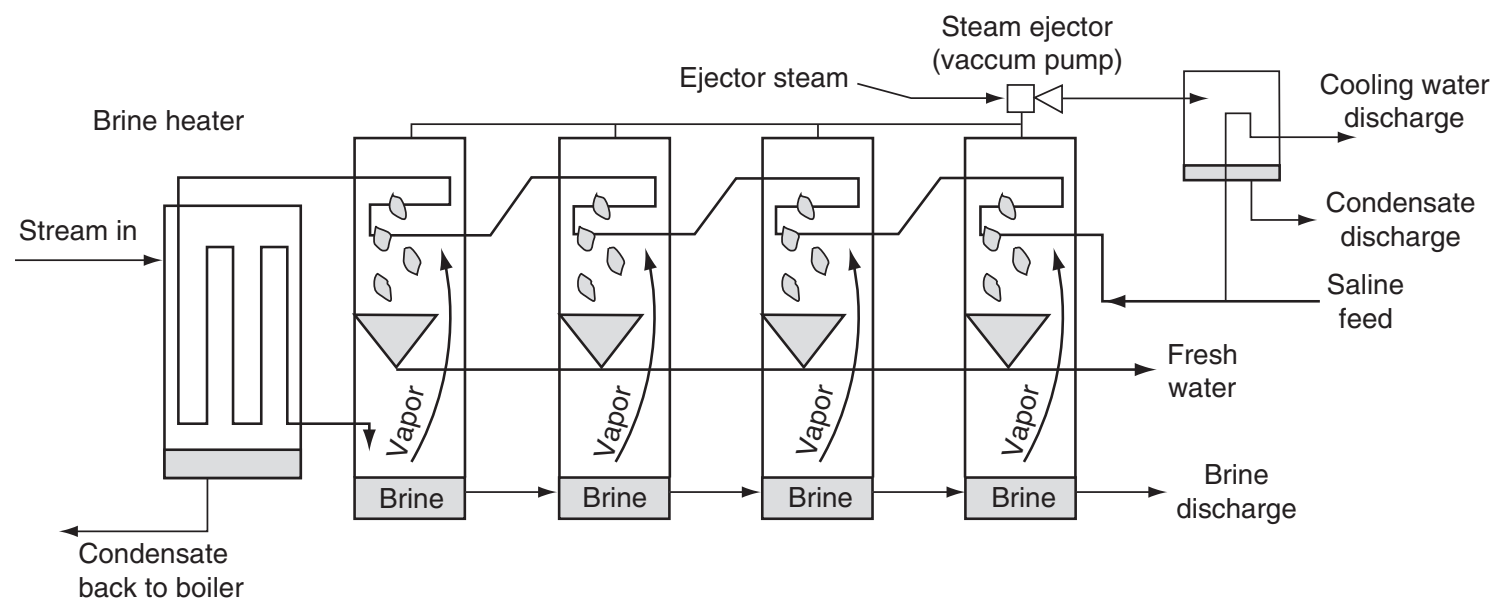

Figure 25 A multistage flash evaporation system with heat recovery.

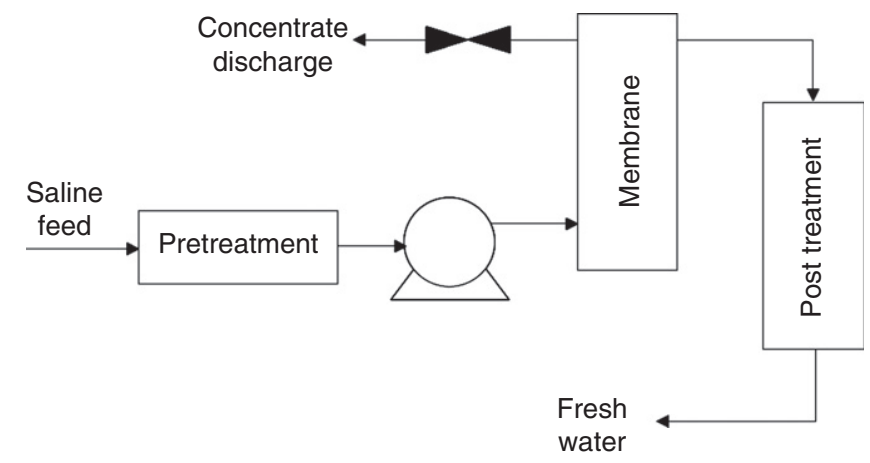

Figure 26 Reverse osmosis.

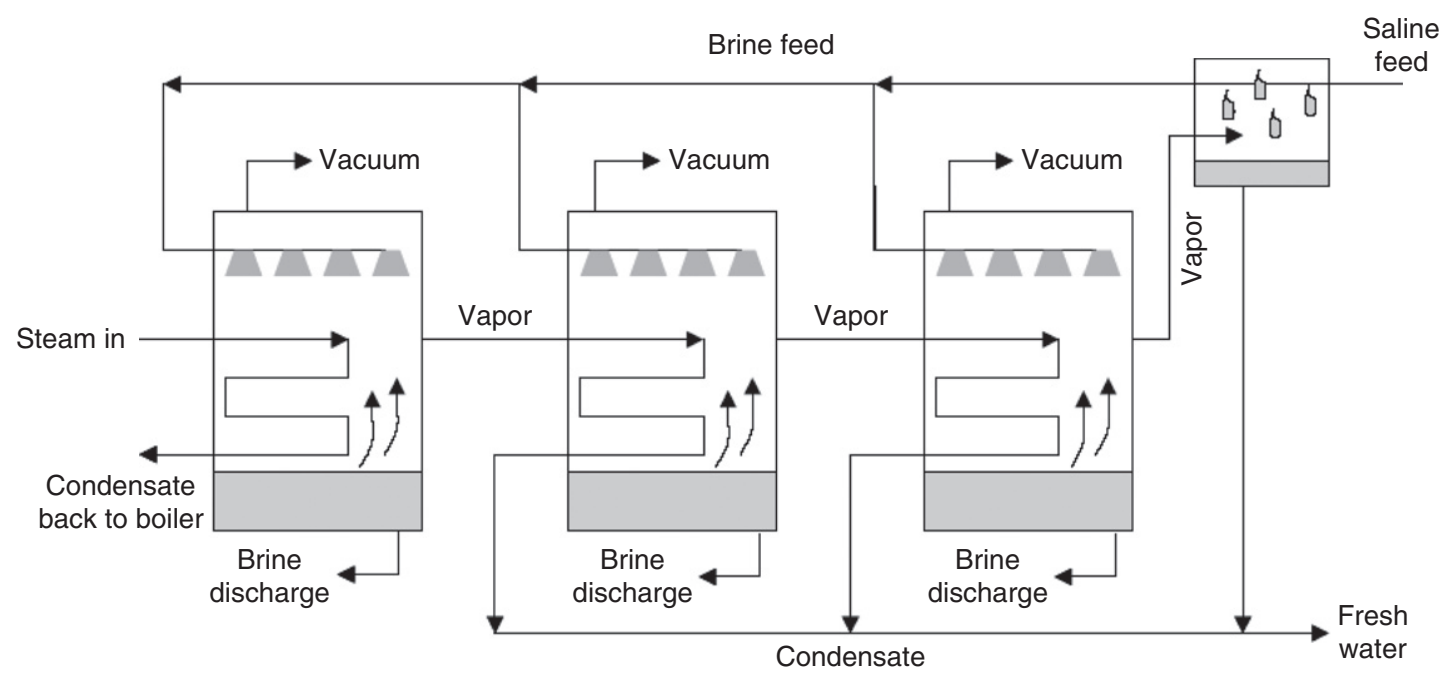

Figure 27 Multieffect evaporation.

In a vapor compression system, water vapor is compressed adiabatically producing a superheated vapor. This is first cooled to saturation temperature and then compressed, using mechanical energy, at constant pressure. In a reverse osmosis system, a pressure gradient across a membrane causes water molecules to pass from one side to the other, but larger mineral molecules cannot penetrate the membrane. A low-temperature solar organic Rankine cycle system for reverse osmosis desalination that operates 
continuously under intermittent solar energy has been shown experimentally to be a technically feasible concept [78]. In electrodialysis, a selective membrane containing positive and negative ions separates water from minerals using solar-generated electricity. A desalination system comprising a concentrating photovoltaic thermal collector and multieffect evaporation desalination plant [79] has been proposed. A feedback linearization control strategy has been developed and applied to a solar collector field supplying process heat to a multiple-effect seawater desalination plant [80]. Solar desalination systems are competitive economically when the solar collector field cost is very low and electricity prices are very high. These circumstances (particularly the latter) prevail in remote arid regions due to the low cost of land and distance from grid-connected electricity. Long-term economic viability is however dependent on effective operation and maintenance. Solar distillation may also be used for the treatment of brackish water withdrawn from wells using photovoltaic-powered pumps [81, 82].

\subsubsection{Passive Basin Stills}

Various diverse forms of passive basin stills using single-effect distillation can be used to supply water to isolated communities or for small supplies of water such as required for emergency drinking water, washing, and battery charging. A typical basin-type solar still consists of an insulated shallow basin lined or painted with a waterproof black material containing a shallow depth (5-20 cm) of saline or brackish water to be distilled and covered with a single-sloped glass aperture, as shown in Figure 24, or a double-sloped one, sealed tightly to reduce vapor leakage. A condensate channel along the lower edge of the glass pane collects the distillate. The still can be fed with saline water either continuously or intermittently, but the supply is generally kept at twice the amount of freshwater produced by the still, depending on initial salinity. Solar radiation transmitted through the transparent cover is absorbed in the water and basin causing the temperature of the water to be raised above that of the cover. Still temperatures above $70{ }^{\circ} \mathrm{C}$ reduce bacterial concentrations significantly [83]. The water loses heat by evaporation, convection, and radiation to the cover and by conduction through the base and edges of the still. The evaporation of water from the basin increases the moisture content in the enclosure and condensation ensues on the underside of the cover; the condensate is then collected via the condensate channels [84]. For passive basin stills, up to $20 \%$ of the potable water production can occur at night [85]. Models have been developed to calculate the solar fraction of single-stage passive solar stills [86].

Passive solar stills for water desalination can be self-operating, of simple construction, relatively maintenance-free, and avoid recurrent expenditure for fuel. The first system, built in Chile in 1872 [87], produced potable water for about 40 years. The advantages of simple passive solar stills are, however, offset by the small amounts of freshwater produced, approximately $2-31 \mathrm{~m}^{-2}$ per day for the simple basin-type solar still [88] and the need for regular flushing of accumulated salts [76]. The performance of the simple basin-type solar still can be improved by integrating the unit with a water heating solar collector. Passing solar-heated water under the basin increases the evaporation rate by increasing the temperature difference between the saline water and the glass cover of the still [89]. Yields can be increased further using a concentrating collector; due to its smaller absorber surface area, thermal losses are reduced significantly resulting in increased thermal efficiency and higher productivity [90]. When a separate flat-plate or concentrating collector is used to increase the water temperature in a still, either pumped or thermosiphonic circulation may be employed to convey water between the still and the collector [91]. Passive solar distillation systems can have an overall efficiency higher than active solar distillation systems [92].

Integral systems replace both separate reflector and still components and their joining pipework with a single multifunctional fabrication leading to lower initial system costs and reduced heat losses. Extensive studies of inverted absorber solar concentrator systems for fluid heating applications [92-96] have shown that their performance can match that of comparable noninverted concentrators. For an inverted absorber solar distillation unit, a double-effect still has also been used successfully to improve output; latent heat of vaporization in the lower vessel was reused to heat the water mass in the upper vessel, which also enhanced condensation in the lower vessel as lower surface temperatures ensued [97]. The incorporation of a basin-type still with an inverted absorber line-axis asymmetric compound parabolic concentrating collector can achieve higher temperatures by minimizing thermal losses by convection suppression. Such systems have been fabricated and characterized experimentally in northern India [98]. An inverted absorber passive basin still as shown in Figure 28 has been found to produce higher water

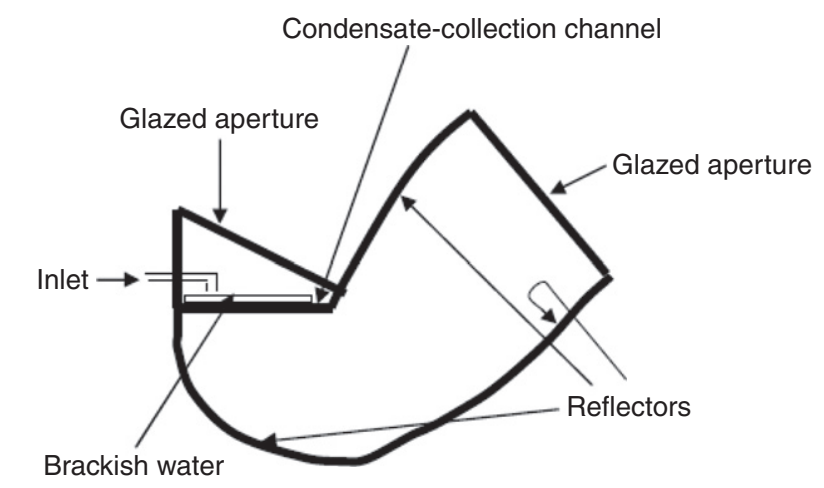

Figure 28 Inverted absorber CPC augmented basin solar still. 
temperatures than comparable direct passive solar stills, thus increasing evaporation and condensation and ultimately producing more potable water based on the same basin area [84]. These higher water temperatures may also have the additional benefit of possibly eliminating more harmful bacteria.

\subsubsection{Solar Refrigeration}

\subsubsection{Types of Solar Refrigeration}

The solar operation of conventional electrical refrigerators, working on a compression cycle, requires the conversion of solar energy into electricity or the conversion of the direct current output of a photovoltaic array using an inverter to an alternating current.

Intermittent vapor absorption refrigeration plants work on a $24 \mathrm{~h}$ cycle comprising heating and refrigeration processes matched to the diurnal operation of the sun: undergoing heating process during the day and producing 'cooling' at night [99]. Porous solids, termed adsorbents, can physically and reversibly adsorb large volumes of a vapor, termed the adsorbate. The concentration of adsorbate vapors in a solid adsorbent is a function of the temperature of the 'working pair' (i.e., mixture of adsorbent and adsorbate) and the vapor pressure of the adsorbate. The dependence of adsorbate concentration on temperature under constant pressure conditions making it possible to adsorb or desorb the adsorbate by varying the temperature of the mixture forms the basis of the solar-powered intermittent vapor sorption refrigeration cycle [100]. An adsorbent-refrigerant working pair for a solar refrigerator requires the following characteristics: (1) a refrigerant with a large latent heat of vaporization; (2) a working pair with high thermodynamic efficiency; (3) a small heat of desorption under the envisaged operating pressure and temperature conditions; and (4) a low thermal capacity. In addition, the operating conditions of a solar-powered refrigerator (i.e., generator and condenser temperature) vary with its geographical location. Water-ammonia has been the most widely used sorption refrigeration pair. The efficiency of such systems is limited by the condensing temperature. For example, cooling towers or desiccant beds have to be used to produce cold water to condense ammonia at lower pressure. Among the other disadvantages inherent in using water and ammonia as the working pair are the following: heavy gauge pipe and vessel walls that are required to withstand the high pressure, the corrosiveness of ammonia, and the problem of rectification (i.e., removing water vapor from ammonia during generation).

When solid absorption using calcium chloride as the absorbent and ammonia as the refrigerant is employed, a reversible chemical reaction takes place when the refrigerant is absorbed by the solid absorbent. To overcome swelling of the volume of up to $400 \%$ when ammonia is absorbed into calcium chloride, a small quantity of another salt is added to the calcium chloride and then mixed with ammonia to prepare a paste, to be heated subsequently in a controlled manner to produce a new granulated absorbent. As the heat of adsorption and desorption for the working pair is high, almost twice the latent heat of evaporation of ammonia, a large combined solar collector/absorber area is required.

Solar refrigeration is employed to cool vaccine stores. The need for such systems is greatest in peripheral health centers in rural communities in the developing world [101, 102]. In the absence of grid-connected electricity, the vaccine cold chain can be extended to these areas with autonomous solar energy vaccine stores. Most of this provision is met by compression cycle refrigerators powered by photovoltaics. Solar thermal refrigeration systems have been the subject of extensive research [103, 104] but have, to date, only rarely led to commercially produced systems.

\subsubsection{Uses of Solar Refrigeration}

An example of practical solar ice making for commercial food storage in rural Mexico [105] illustrates the use of solar energy in remote, non-grid-connected areas. The system consists of seven double intermittent ammonia-water absorption cycle ice makers, three of which are ground-mounted to generate ice for processing fish and transporting it to market, and four, mounted on the root of the storage building, to provide ice to cool a storage tank. Each double intermittent ammonia-water absorption cycle device is supplied with heat by a $12 \mathrm{~m}^{2}$ aperture area parabolic trough concentrating solar collector and has produced about $68 \mathrm{~kg}$ of ice daily since late 1992. The $84 \mathrm{~m}^{2}$ total parabolic trough solar collector area provides annually a $519 \mathrm{GJ}$ heat input giving an annual $72.8 \mathrm{GJ}$ of refrigeration.

\section{Acknowledgments}

The author would like to thank Professor Philip Eames, University of Loughborough, Professor Valentine Ekechukwu, University of Nigeria, Professor Yigsaw Yohanis, University of Ulster, Professor G. N. Tiwari, IIT Delhi, Dr. Mervyn Smyth, University of Ulster, and Dr. Steve Lo, University of Bath, for their various insights and collaborations on solar industrial and agricultural systems over many years. He would also like to thank Ms. Gillian Collins, who produced many of the diagrams and tables in this chapter.

Solar energy research undertaken by the author is supported by Science Foundation Ireland under grants SFI 07/RFP/ENE 719 and SFI 05/RFP/ENE 025. 


\section{References}

[1] Kalogirou S (2003) The potential for solar industrial process heat applications. Applied Energy 76: 337-361.

[2] Weiss W, Schweiger H, and Battisti R (2005) Market potential and system designs for industrial heat applications. Proceedings of ESTEC, 2005 - 2nd European Solar Thermal Energy Conference. Freiburg, Germany, 21-22 June.

[3] Norton B (1999) Renewable electricity, what is the true cost? IEE Power Engineering Journal 13: 6-12.

[4] Butti K and Perlin J (1980) A Golden Thread. New York: Van Nostrand Reinhold Co.

[5] Rabl A (1985) Active Solar Collectors and Their Application. New York: Oxford University Press.

[6] Reddy TA (1987) The Design and Sizing of Active Solar Thermal Systems. Oxford, UK: Clarendon Press.

[7] Duffie JA and Beckman WA (1991) Solar Engineering of Thermal Processes, 2nd edn. New York Wiley Interscience.

[8] Norton B (1992) Solar Energy Thermal Technology. Heidelberg, Germany: Springer-Verlag.

[9] Goswami DY, Kreith F, and Kreider JF (1999) Principles of Solar Engineering, 2nd edn. New York: John Wiley and Sons.

[10] Norton B (2001) Solar process heat: Distillation, drying, agricultural and industrial uses. In: Gordon J (ed.) Solar Process Heat: Distillation, Drying, Agricultural and Industrial Uses, Solar Energy; State of the Art, pp. 477-496. London: James \& James.

[11] Tiwari GN (2002) Solar Energy, Fundamentals, Design, Modelling and Applications. New York: CRC Press.

[12] Prapas DE, Norton B, and Probert SD (1986) Sensor system for aligning a single-axis tracker with direct solar insolation. Applied Energy 25: 1-8.

[13] Kim DH, Jenkins BM, Yore MW, and Kin NJ (2007) Salt recovery from agricultural drainage water using a liquid film solar-assisted concentrator - simulation and model validation. Solar Energy 81: 1314-1321.

[14] Dubener J, Helsh G, Moiseev A, and Bornhoft M (2008) Glasses for solar energy conversion systems. Journal of the European Ceramic Society 29: $1203-1210$.

[15] Burek SAM, Norton B, and Probert SD (1989) Transmission and forward scattering of insolation through plastic (transparent and semi-transparent) materials. Solar Energy 42: $457-475$.

[16] Norton B and Edmonds JEJ (1991) Aqueous propylene glycol concentrations for the freeze protection of thermosyphon solar energy water heaters. Solar Energy 47: 375-382.

[17] Häberbe A, Berger M, Luginsland F, and Zahler C (2008) Experience with linear concentrating Fresnel collectors for process heat applications. 14th International Symposium on Concentrating Solar Power and Chemical Energy Technologies. Las Vegas, NV, USA.

[18] Alnaser W and Alnaser N (2009) Solar and wind potential in GCC countries and some related projects. Journal of Renewable and Sustainable Energy 1: 2.

[19] Russel JL, Schuster JR, and Eggers GH (1997) Development status of the fixed mirror solar concentrator. Proceedings of the 12th Intersociety Energy Conversion Engineering Conference, Honolulu, Hawaii, pp. 1141-1146.

[20] Martinez Moll V, Pujol Nadal R, Molá Pol A, and Schweiger H (2006) Analysis of a stationary parabolic linear concentrator with tracking absorber. 13th International Symposium on Concentrating Solar Power and Chemical Energy Technologies. Seville, Spain.

[21] Abdel-Salam HEA, Probert SD, and Norton B (1986) Predicted performances of coffered solar ponds in the U.K. and Egypt. International Journal of Physico-Chemical Hydrodynamics 7: 217-233.

[22] Smyth M and Skates H (2009) A passive solar water heating system for vineyard front protection. Solar Energy 83: 400-408.

[23] Eames PC and Norton B (1998) The effect of tank geometry on thermally stratified sensible heat storage subject to low Reynolds number flows. International Journal of Heat and Mass Transfer 41: 2131-2142.

[24] Farrell AJ, Norton B, and Kennedy DM (2006) Corrosive effects of salt hydrates phase change materials used with aluminium and copper. Journal of Materials Processing Technology 175: 198-205.

[25] Yohanis YG, Popel 0, Frid SE, and Norton B (2006a) Geographic variation of solar water heater performance in Europe. Proceedings of the Institution of Mechanical Engineers, Part A, Journal of Power and Energy 220: 395-407.

[26] Yohanis YG, Popel 0, Frid SE, and Norton B (2006b) The annual number of days that solar heated water satisfies a specified demand temperature. Solar Energy 80(8): 1021-1030.

[27] Bourges B, Adnot J, Campana D, et al. (1980) Provision of long term average performance of low temperature solar systems: A synthetical review of existing methods and available meteorological data, ICBEM, Portugal.

[28] Luna D, Nadeau JP, and Jannot Y (2009) Solar timber kilns: State of the art and foreseeable developments. Renewable and Sustainable Energy Reviews 13: 1446-1455.

[29] Erbs DG, Klein SA, and Duffie JA (1982) Estimation of the diffuse radiation fraction for hourly, daily and monthly average global radiation. Solar Energy 25: 293-302.

[30] Karatasou S, Santamouris M, and Geros V (2006) On the calculation of solar utilizability for south oriented flat plate collectors tilted at an angle equal to the local latitude. Solar Energy 80: 1600-1610.

[31] Gordon JM and Rabl A (1982) Design, analysis and optimization of solar industrial process heat plants without storage. Solar Energy 28: 519-530.

[32] Braun JE, Klein SA, and Beckman WA (1981) Seasonal storage of energy in solar heating. Solar Energy 26: 403-411.

[33] Oliveira AC (2007) A new look at the long-term performance of general solar thermal systems. Solar Energy 81: 1361-1368.

[34] Klein SA, Beckman WA, and Duffie JA (1976) A design procedure for solar heating systems. Solar Energy 18: 113-127.

[35] Klein SA, Beckman WA, and Duffie JH (1977) A design procedure for solar air heating systems. Solar Energy 19: 509-512.

[36] Collares-Pereira M, Gordon JM, Rabl A, and Zarmi Y (1984) Design and optimisation of solar industrial hot water systems with storage. Solar Energy 32: 121-133.

[37] Baer D, Gordon JM, and Zarmi Y (1985) Design and optimization of solar steam systems for constant load applications. Solar Energy 35: 137-151.

[38] Kulkarni GN, Kedere SB, and Bandyopadhyay S (2008) Design of solar thermal systems utilising pressurised hot water storage for industrial applications. Solar Energy 82: 686-699.

[39] Klein SA, Beckmann B, and Duffie J, et al. (2009) TRNSYS Program Manual. Solar Energy Laboratory, University of Wisconsin-Madison, USA.

[40] Casavant TE and Côté RP (2004) Using chemical process simulation to design industrial ecosystems. Journal of Cleaner Production 12: 901-908.

[41] Kalogirou SA (2004) Optimisation of solar systems using artificial neural-networks and genetic algorithms. Applied Energy 77: 383-405.

[42] Tripathy PP and Kumar S (2008) A methodology for determination of temperature dependant mass transfer coefficients from drying kinetics: Application to solar drying. Journal of Food Engineering 90: 212-218.

[43] Sharma A, Chen CR, and Lan NV (2009) Solar-energy drying systems: A review. Renewable and Sustainable Energy Reviews 13: 1185-1210.

[44] Hassanain A, Norton B, and Eames PC (1998) An experimental investigation into solar chimney designs suitable to augment crop dryers. Renewable Energy 16: 2223-2226.

[45] Ferreira AG, Maia CB, Cortez MFB, and Valle RM (2008) Technical feasibility assessment of a solar chimney for food drying. Solar Energy 82: 198-205.

[46] Forson FK, Nacha MAA, and Rajakaruna H (2007) Modelling and experimental studies on a mixed-mode natural circulation solar crop-dryer. Solar Energy 81: 346-357.

[47] Ekechukwu OV and Norton B (1999) Effects of seasonal weather variations on the measured performance of a natural circulation solar energy tropical crop dryer. Energy Conversion and Management 39: 1265-1276.

[48] Hossain M and Bala BK (2007) Drying of hot chilli using solar tunnel drier. Solar Energy 81: 85-92.

[49] Suthi VP and Avosa S (2009) Improvement in greenhouse solar drying using inclined north wall reflection. Solar Energy 83: 1472-1484.

[50] Janjai S, Lamlest N, Intaivee P, et al. (2009) Experimental and simulated performance of a PV-ventilated solar greenhouse dryer for drying peeled longan and banana. Solar Energy 83: 1550-1565.

[51] Barnwal P and Tiwari A (2008) Design, construction and testing of hybrid photovoltaic integrated greenhouse dryer. International Journal of Agricultural Research 3: 110-120.

[52] Fargali H, El-Shafly A, Nafeh A, et al. (2008) Medicinal herb drying using a photovoltaic array and a solar thermal system. Solar Energy 82: 1154-1160. 
[53] Cronin K, Norton B, Taylor J, et al. (1996) Development of a simulation tool to enable optimisation of the energy consumption of the industrial timber drying process. Applied Energy 53: 325-340.

[54] Khatry AK, Sodha MS, and Malik MAS (1978) Periodic variation of ground temperature with depth and time. Solar Energy 20: 425-427.

[55] Smitabhindu R (2008) Optimisation of Solar Assisted Drying System for Drying Bananas. PhD Thesis, Kasetsart University.

[56] Romàn R, Caňades I, Rodríguez J, et al. (2008) Solar sintering of alumina ceramics: Microstructural development. Solar Energy 82: 893-902.

[57] Haueter P, Seitz T, and Steinfeld A (1999) A new high flux solar furnace for high-temperature thermochemical research. ASME Journal of Solar Energy Engineering 121: 77-80.

[58] Hare JG, Norton B, and Probert SD (1984) Design of greenhouses; thermal aspects. Applied Energy 18: 49-82.

[59] Tiwari GN (2003) Greenhouse Technology for Controlled Environment. New Delhi, India: Narosa Publishing House.

[60] Abak KA, Bascetincelik A, Baytorun N, et al. (1994) Influence of double plastic cover and thermal screens on greenhouse temperature, yield and quality of tomato. Acta Horticulturae 369: 149-154.

[61] Bailey BJ (1981) The evaluation of thermal screens on greenhouses in commercial nurseries. Acta Horticulturae 115: 663-670.

[62] Santamouris M, Mihalakakou G, Balaras CA, et al. (1996) Energy conservation in greenhouses with buried pipes. Solar Energy 21: 353-360.

[63] Ghosal MK and Tiwari GN (2006) Modelling and parametric studies for thermal performance of an earth to air heat exchanger integrated with a greenhouse. Energy Conservation and Management 47: 1779-1798.

[64] Shukla A, Tiwari GM, and Sodha MS (2006) Thermal modeling for greenhouse heating by using thermal curtain and an earth-air heat exchanger. Building and Environment 41: 843-850.

[65] Santamouris M, Balaras CA, Dascalaki E, and Vallindras M (1994) Passive solar agricultural greenhouses: A worldwide classification and evaluation of technologies and systems used for heating purposes. Solar Energy 53: 411-426.

[66] Gauthier C, Lacroix M, and Bernier H (1997) Numerical simulation of soil heat exchanger - storage systems for greenhouses. Solar Energy 60: 333-346.

[67] Sethi VP and Sharma SK (2007) Survey of cooling technologies for worldwide agricultural greenhouses. Solar Energy 81: 1447-1459.

[68] Sethi VP and Sharma SK (2008) Survey and evaluation of heating technologies for worldwide agricultural greenhouse applications. Solar Energy 82: 832-859.

[69] Fang Y, Eames PC, Norton B, et al. (2008) The thermal performance of an electrochromic vacuum glazing with selected low-emittance coatings. Thin Solid Films 516: 1074-1081.

[70] Janjai S, Srisittipokakun N, and Bala BK (2007) Experimental and modeling performance of a roof-integrated solar drying system for drying herbs and spices. Solar Energy 33 91-103.

[71] Norton B, Hobday RA, and Lo SNG (1992) Thermosyphoning air panels. Advances in Solar Energy 7: 495-571.

[72] Norton B, Eames PC, Yadav YP, and Griffiths PW (1997) Inverted absorber solar concentrators for rural applications. International Journal of Ambient Energy 18: 115-120.

[73] Schwarzer K and Vierada Silva ME (2008) Characterisation and design method of solar cookers. Solar Energy 82: 157-165.

[74] Funk PA and Larson DL (1998) Parametric model of solar cooker performance. Solar Energy 62: 63-68.

[75] WHO (1996) Guidelines for Drinking-water Quality, vol. 2, pp. 940-949. Geneva, Switzerland: World Health Organization.

[76] Malik MAS, Tiwari GN, Kumar A, and Sodha MS (1982) Solar Distillation. Oxford, U.K.: Pergamon Press.

[77] Kalogirou SA (2005) Seawater desalination using renewable energy sources. Progress in Energy and Combustion Science 31: 242-281

[78] Monolakos D, Kosmadakis G, Kyritsis S, and Papadulis G (2009) On-site experimental evaluation of a low temperature solar organic Rankine cycle system for RO desalination. Solar Energy 83: 646-656.

[79] Mittelmen G, Kribus A, Mouchtan 0, and Dayan A (2009) Water desalination with concentrating photovoltaic/thermal (CPVT) systems. Solar Energy 83: 1322-1334.

[80] Roca L, Berengivel M, Yebra L, and Alarcon-Padilla DC (2008) Solar field control for desalination plans. Solar Energy 82: 772-786.

[81] Odeh I, Yohanis YG, and Norton B (2006) Influence of pumping head, insolation and PV array size on PV water pumping system performance. Solar Energy 80: 51-64.

[82] Odeh I, Yohanis YG, and Norton B (2006) Economic viability of photovoltaic water pumping systems. Solar Energy 80: 850-860.

[83] Tiwari GN and Prasad B (1996) Thermal modelling of concentrator assisted solar distillation with water flow over the glass cover. International Journal of Solar Energy 18: 173-190.

[84] Smyth M, Norton B, and Byers W (2005) Measured effect of reflector augmentation of simple basin type passive solar skills. International Journal of Ambient Energy 25: 59-70.

[85] Yates A and Woto T (1988) Small Scale Desalination for Areas of Botswana. Ottawa, Canada: International Development Centre.

[86] Madlopa A and Johnstone C (2009) Model for computation of solar fraction in a single slope solar still. Solar Energy 83: 873-882.

[87] Harding J (1883) Apparatus for solar distillation. Proceedings of the Institution of Civil Engineering 73: 284-288.

[88] Zaki CM, Al-Turki A, and Fattani M (1992) Experimental investigation on concentrator assisted solar stills. Solar Energy 11: 193-199.

[89] Soleman SE (1976) Water Distillation by Solar Energy. PhD Thesis, Faculty of Engineering, Keio University.

[90] Zaki CM, Radhwan AM, and Balbeid AO (1993) Analysis of assisted coupled solar stills. Solar Energy 51(4): 277-258.

[91] Singh SK, Bhatnagar P, and Tiwari GN (1996) Design parameters for concentrator assisted solar distillation system. Energy Conversion Management 37(2): 247-252.

[92] Tiwari GN (1992) Recent Advances in Solar Distillation. Solar Energy and Energy Conservation. New Delhi, India: Wiley Eastern.

[93] Kothdiwala AF, Eames PC, and Norton B (1996) Optical performance of an asymmetric inverted absorber compound parabolic concentrating solar energy collector. Renewable Energy 9: 576-579.

[94] Kothdiwala AF, Eames PC, and Norton B (1997) Experimental analysis and performance of an asymmetric inverted absorber compound parabolic concentrating solar energy collector at various absorber gap configurations. Renewable Energy 10: 235-238.

[95] Kothdiwala AF, Eames PC, and Norton S (1999) Asymmetric line-axis inverted absorber compound parabolic concentrating optical parameter analysis. Institution of Mechanical Engineering Journal of Mass, Power and Energy 213(A): 143-148.

[96] Kothdiwala AF, Eames PC, Norton B, and Zacharopoulos A (1999) Comparison between inverted absorber arrangements and symmetric tubular absorber compound parabolic concentrating solar collectors. Renewable Energy 18: 277-281.

[97] Suneja S, Tiwari GN, and N Rai,S (1997) Parametric study of an inverted absorber double-effect solar distillation system. Desalination 109: 177-186.

[98] Yadav VP, Eames PC, and Norton B (1998) A double-evaporative single-basin solar still for high temperature solar distillation. Proceedings of the 5th World Renewable Energy Congress, pp. 2376-2379. Florence, Italy.

[99] Alghoul MA, Sulaiman MY, Azmi BZ, and Wahab MA (2007) Advances in multi purpose solar adsorption systems for domestic refrigeration and water heating. Applied Thermal Engineering 27: 813-822.

[100] Fan Y, Luo L, and Souyri B (2006) Review of solar sorption refrigeration technologies: Development and applications. Renewable and Sustainable Energy Reviews 11: 1758-1775.

[101] Wirkas T, Toikilik S, Miller N, et al. (2007) A vaccine cold chain freezing study in POVG highlights needs for hot climate countries. Vaccine 25: 691-697.

[102] Berhane $Y$ and Demissie M (2000) Cold-chain status at immunisation centres in Ethiopia. East Africa Medical Journal 77: 476-479.

[103] Hammad M and Habali S (2000) Design and performance study of a solar energy powered vaccine cabinet. Applied Thermal Engineering 20: 1785-1798.

[104] Uppal AH, Norton B, and Probert SD (1986) A low-cost solar-energy stimulated absorption refrigerator for vaccine storage. Applied Energy 25: 167-174.

[105] Erickson DC (1994) Solar Icemakers in Maruata. Solar Today, July/August. 